CHAPTER 35

\title{
The Worked Flint
}

\section{Chantal Conneller, Aimée Little, Virginia Garcia-Diaz and Shannon Croft}

\section{Introduction}

Techniques, both those of excavation and those associated with lithic analysis, have improved considerably since Clark excavated Star Carr. These have resulted in more detailed and different types of information being recovered from the lithic assemblage. However, we remain motivated by Clark's aim in excavating Star Carr: 'to understand how [people] lived in the past' (Clark 1939, 1), and our improved methods of excavation and techniques of analysis have been focused on this end. For example, our focus on full recovery and retention of all lithics, in contrast to Clark, has had an impact on understanding the lithic assemblage. Clark famously did not retain material smaller than 'finger-nail size' $(1954,96)$, nor did he sieve sediment. This resulted in the recovery of only 15 microburins. Our excavations have yielded 85 (admittedly in an assemblage around 50\% larger), 31 of which were recovered from sieving. Clark was keen to pioneer new scientific techniques, and we have deployed microwear and residue analysis to more fully understand activities at the site.

Following the original publication, the lithics have played a relatively minor role in the subsequent reinterpretations, which have mainly focused on the unusual patterning of faunal remains retained from Clark's excavations (e.g. Caulfield 1978; Andresen et al. 1981; Legge and Rowley-Conwy 1988). However, Jacobi based his interpretations of the settlement patterns in Northern England on the tools found at Star Carr and sites on the North York Moors respectively (1978), while Pitts (1979) used the presence of scrapers and awls to suggest skin-working was the major function of the site. More recently Mellars (2009) used the location and composition of 'lithic scatters' to argue for in situ activity in the lake and wetland edge.

The only new analysis of lithic material since Clark's excavations was made by Dumont $(1983 ; 1988 ; 1989)$, who carried out an in-depth analysis of a selection of tools from Clark's excavations. Dumont was critical of the craft focus taken by Pitts and Andersen, which he summarised as craft and manufacturing activities undertaken as 'boredom reducers' whilst waiting for and processing game. Instead he undertook analysis with a view to evaluate presence versus absence of activities and to 'add fuel to the function of the site as a whole' (1983, 128). Unlike the research presented here, Dumont's analysis had no spatial focus (other than the general knowledge that pieces analysed were taken from Clark's area); thus, no comparison of the structuring of activities, as represented by tool use, can be made between his work and that presented here. Despite Dumont's analysis focusing on select artefact types, with no spatial reference, he concluded that the range of activities reflected

How to cite this book chapter:

Conneller, C., Little, A., Garcia-Diaz, V. and Croft, S. 2018. The Worked Flint. In: Milner, N., Conneller, C. and Taylor, B. (eds.) Star Carr Volume 2: Studies in Technology, Subsistence and Environment, pp. 493-534. York: White Rose University Press. DOI: https://doi.org/10.22599/book2.u. Licence: CC BY-NC 4.0 
in tool use at Star Carr were too diverse to justify the site being defined as a tannery or hunting blind (as suggested by Pitts 1979 and Andersen et al. 1981). Instead, he suggested that it probably functioned as a base camp.

\section{Methods}

All lithics underwent initial identification and cataloguing using the typological system of Healy (1988), with microliths recorded according to Jacobi types (Jacobi 1981) and burin types following Inizan et al. (1991). The presence of retouch and macroscopic edge damage was also recorded on blanks. Extent of cortex was recorded in five categories $(0,0-25 \%, 25-50 \%, 50-75 \%, 75-100 \%, 100 \%)$, in order to understand variation in the reduction sequences across site. Lithic material was assigned to raw material type (either till, Wolds or chert) on the basis of the work of Henson (1982), plus additional sampling carried out by CC. Condition of the cortex was recorded as pebble, derived and chalk in order to understand where material was obtained. Colour was also recorded to investigate whether certain colours of flint were preferentially used for particular tools.

Refitting was employed to understand reduction sequences, movement of material around the site and as a taphonomic tool. Due to the large size of the excavation area and its lithic assemblage, and the time constraints of the project, only certain areas were targeted for refitting. These focused on the larger areas of open excavation where chances of success were greater, whilst areas heavily truncated by earlier excavations, such as Clark's area and Moore's area, were avoided. We also avoided wetland assemblages, as these represent tool use and deposition rather than in situ knapping, though wetland edge assemblages were included. Selective refitting was employed in some areas. The lithic assemblage from the western structure was highly burnt and fragmented (making refitting difficult) and was also extremely large; this area was sampled by selecting only red and black flint for refitting. This sample of rarer and distinctive colours was investigated to understand whether the material in this area represented in situ activity or middening. Material selected for refitting was laid out on trays and sorted by material, colour and cortex. Refits were temporarily stuck together using blu-tack (subsequent to selection of material for microwear and residue analysis), but longer sequences were glued, following analysis, using a water-based glue dissolvable in acetone. Refitting was carried out by CC, with some contribution from Julie Birchenall and University of York students (Chapter 8 presents the main results).

Microwear analysis was carried out by AL with assistance from VGD (see Chapter 15 for methods). Artefacts for microwear were selected by CC following initial techno-typological analysis of the assemblage. These consisted of a representative sample of major tool types and blades and flakes, both unmodified and with macroscopic edge damage or retouch. An additional consideration when selecting this sample was to provide coverage of activities across the entire site. Material for microwear analysis was selected before the start of the refitting exercise in order to avoid possibility of damage to the material. However, on occasion it was deemed useful to investigate material for microwear because it belonged in a refit sequence (e.g. due to the presence of a long distance refit). In this case the piece was sent for microwear immediately on discovering the refit to minimise damage.

Residue analysis was carried out by SC. This involved conducting both a burial experiment to examine the potential survival of different types of residues within this burial environment (Croft et al. 2016) and examining a sample of archaeological worked flint. Lithics to be sampled for residue analysis were not handled and were placed into a clean finds bag using a trowel. A separate sample of soil from underneath the artefact was also sampled. A number of residues were observed using reflected visible light microscopy (VLM) and then examined further using scanning electron microscope with energy dispersive x-ray spectroscopy (SEM-EDS or SEM-EDX), gas chromatography-mass spectrometry (GC-MS), confocal Micro-Raman, and Fourier transform infrared microspectroscopy (FTIRM). Unfortunately, most residues seen on stone tools were natural: minerals such as iron oxide, gypsum and iron pyrites were common, as found in the analysis of the degradation of the site (Chapter 22). However, preliminary microscopic and GC-MS evidence suggested pine (likely Pinus sylvestris) compounds were present in trace amounts on nine stone tools (Croft 2017).

\section{The assemblage}

A total of 24,883 pieces of flint were recovered from the excavations, testpitting and fieldwalking at Star Carr between 2004 and 2015 (Table 35.1). This is a larger assemblage than that recovered by Clark $(n=16,937)$, but 


\begin{tabular}{|c|c|c|}
\hline Category & No. & $\%$ \\
\hline Tools total: & 2475 & 9.95 \\
\hline Awl & 69 & 0.28 \\
\hline Axe & 21 & 0.08 \\
\hline Burin & 232 & 0.93 \\
\hline Denticulate & 22 & 0.09 \\
\hline Hammerstone & 12 & 0.05 \\
\hline Microdenticulate & 23 & 0.09 \\
\hline Microlith & 312 & 1.25 \\
\hline Notch & 14 & 0.06 \\
\hline Scraper & 342 & 1.37 \\
\hline Scraper/burin & 10 & 0.04 \\
\hline Strike-a-light & 20 & 0.08 \\
\hline Truncation & 31 & 0.12 \\
\hline Wedge & 5 & 0.02 \\
\hline Retouched & 115 & 0.46 \\
\hline Utilised blade & 727 & 2.92 \\
\hline Utilised flake & 205 & 0.82 \\
\hline Utilised fragment & 315 & 1.26 \\
\hline Tool spalls total: & 438 & 1.76 \\
\hline Axe flake & 106 & 0.42 \\
\hline Burin spall & 231 & 0.93 \\
\hline Microburin & 89 & 0.36 \\
\hline Retouch spall & 12 & 0.05 \\
\hline Core prep. total: & 497 & 2 \\
\hline Core tablet & 219 & 0.88 \\
\hline Crested blade & 202 & 0.81 \\
\hline Plunging & 60 & 0.24 \\
\hline Step fracture removal & 16 & 0.06 \\
\hline Debitage total: & 21473 & 86.29 \\
\hline Blade & 3081 & 12.38 \\
\hline Flake & 4867 & 19.56 \\
\hline Fragment & 9814 & 39.44 \\
\hline Chip & 2984 & 11.99 \\
\hline Core & 322 & 1.29 \\
\hline Core fragment & 52 & 0.21 \\
\hline Nodule & 12 & 0.05 \\
\hline Chunk & 341 & 1.37 \\
\hline Total & 24883 & 100 \\
\hline Burnt & 4117 & 16.54 \\
\hline
\end{tabular}

Table 35.1: The Star Carr assemblage. 
using more systematic recovery methods, and over a much larger area. Clark thus seems to have encountered, in general, much higher densities of materials. Nearly $10 \%$ of recovered artefacts from the current excavations are tools, with the assemblage fairly 'balanced' (Mellars 1976) between scrapers $(n=342)$, microliths $(n=312)$ and burins $(n=232)$, though this distinction is pretty meaningless for a site that has seen intermittent occupation for round 800 years (Chapter 17). Clark's figures for essential tools are slightly different, with burins most common $(n=334)$, followed by scrapers $(n=326)$ and microliths $(n=248)$, the lower quantities of the latter possibly due to a lack of sieving. Clark also had rather more awls $(n=114)$ than recovered during the current excavations $(n=69)$. The increased number of awls and burins in Clark's excavations reflects the higher numbers of awls in the western part of the site (see Chapter 8) and the large number of burins in the area of wetland deposition represented in the southern part of Clark's cutting I, also encountered during these excavations. $16.5 \%$ of the lithic material from the current excavations is burnt, a result of intensive activities round hearths in the dryland area of the site. The spatial dimensions of lithic-focused activities have been discussed in Chapter 8. This chapter therefore investigates different aspects of the assemblage; the raw materials used, the technology employed, and the form, manufacture and curation of the tools recovered. Given the extraordinary temporal resolution of the site, this chapter also explores changes in traditions of lithic manufacture and tool production over time.

\section{Sources}

Two types of flint were employed for the vast majority of the assemblage: till flint and Wolds flint. Chert is present but rare. Till flint was most commonly used: this material is extremely heterogeneous, varying considerably in colour and quality. Most common is semi-translucent grey speckled flint but a clear brown flint (ranging in hue from honey coloured to black) and less commonly a red speckled flint is also present. The clear brown flint is of best quality, with fewer irregularities and flaws. The grey and red speckled flint are of variable quality; some nodules are relatively translucent and fine, others coarser, with inclusions and flaws, such as voids and fossils.

Till flint can be obtained either directly from the exposures of glacial till that blanket the east coast, or in a further derived source such as stream or river cobbles, or as beach pebbles. The characteristics of the cortex of the material recovered from Star Carr suggest the majority of the material was obtained as beach pebbles. The remainder was probably obtained directly from the till. Clear brown flint was suggested by Clark to be from a different source to the grey till flint. A few pieces of this flint (often tabular) do have a slightly different cortex, possibly indicating a cobble or closely-derived source, potentially from the current region of south Lincolnshire or an off-shore source. However, the vast majority of this brown flint also has a beach pebble cortex, indicating it was obtained in the same manner as the speckled grey flint.

The exact means of procurement from the till is uncertain, but the large exposures of till cliffs created by coastal erosion are a likely source. Today a range of materials can be procured from East Yorkshire beaches, from small pebbles with a heavily battered cortex, to larger tabular and semi-tabular pieces with a thin sharp cortex, which can be obtained freshly eroded from the cliffs of glacial till that back many of the beaches in the region. While glacial till is present in the Vale of Pickering itself, flint is not a major component of this deposit. The Devensian ice sheet that deposited the glacial till was a two-tier glacier, resulting in differences in the character of the till deposited by each. The lower Skipsea Till contains larger amounts of chalk and flint, and these gradually increase southwards, suggesting that the ice was in fairly continuous contact with the chalk that extends east from the Yorkshire Wolds beneath the North Sea (Madgett and Catt 1978; Catt 1987). Deposits of the overlying Withernsea Till are less extensive; however, Foster (1985) suggests that the till which blankets the eastern end of the Vale of Pickering, existing as surface deposits at least as far as Seamer, is of Withernsea type. As the upper glacier that deposited the Withernsea Till overrode the lower one, before entering the Vale of Pickering, it contains little flint, having never been in contact with the chalk. What flint is present is extremely small and weathered, suggesting that this material was already from a derived source before becoming incorporated into the glacier. This means that it is unlikely that Mesolithic people obtained any flint from the till of the Vale, and instead they would have had to range further afield.

Beach pebbles were used as the predominant source throughout the period, from the earliest occupation of the site (represented by lithic material in the detrital wood scatter), to the latest (represented by the fen peat scatter) (Table 35.2). Sea-level rise was transforming coastal geomorphology immediately to the east of the Vale of Pickering during the Early Mesolithic (Shennan et al. 2006), bringing the coast ever closer. Ascertaining 


\begin{tabular}{|l|l|r|r|r|r|r|}
\hline & \multicolumn{1}{|l|}{ c. $\mathbf{9 3 0 0 - 9 0 0 0 ~ c a l ~ B C ~}$} & c. $\mathbf{8 9 5 0}$ cal BC & c. $\mathbf{8 8 5 0}$ cal BC & c. $\mathbf{8 8 0 0}$ cal BC & c. $\mathbf{8 7 0 0}$ cal BC & c. $\mathbf{8 5 0 0}$ cal BC \\
\hline $\begin{array}{l}\text { Cortex } \\
\text { type (\%) }\end{array}$ & Detrital wood & Central platform & Axe workshop & Clark's area & SC22 scatter & Fen scatter \\
\hline Chalky & 8.33 & 13.64 & 10.71 & 8.33 & 13.04 & 13.95 \\
\hline Derived & 4.17 & 18.18 & 32.14 & 26.04 & 13.04 & 16.28 \\
\hline Pebble & 87.5 & 68.18 & 57.14 & 65.63 & 73.92 & 69.77 \\
\hline
\end{tabular}

Table 35.2: Representation of till cortex types in dated assemblages.

source from cortex is not an exact science, as even beach pebbles can have areas of thicker chalky cortex preserved in dips or as a result of recortication. However, there do seem to be some possible temporal differences in the relative use of beach pebbles and nodules obtained more directly from the till. During the earliest occupation of the site c. 9300-9000 cal BC (as represented by material from the detrital wood scatter), beach pebbles predominated. During the main phase of occupation of the site 9000-8700 cal BC, represented by the central platform, Clark's area, and the axe workshop, use of material direct from the till increased. In the later phases of the site, at the SC22 scatter and the Fen Carr scatter, use of beach pebbles increases slightly. This is likely to reflect a number of factors, most likely the morphology of the changing coastline, but also perhaps shifting mobility patterns and desire for better quality material.

The size of till flint depends on its source. Larger nodules can be obtained directly from the till. In general material obtained from the beach is smaller, with refitted material indicating small to medium-sized pebbles being deployed. Today relatively large nodules of flint can be obtained from east coast beaches, and the same is likely to be true in the Mesolithic. However, these are less ideal for a technology based on bladelet production and also would be more difficult to transport to Star Carr. While caches reveal that sometimes large nodules were brought in whole, on other occasions they were split, probably at source, into smaller packages. Preformed cores from a cache that mostly refit into a larger nodule average at a core height of $56.4 \mathrm{~mm}$ and very similar width and depth, averaging $38.75 \mathrm{~mm}$ and $38.5 \mathrm{~mm}$. These packages were more easily transportable and more useful for the production of small blades and bladelets.

The quality of material is also affected by source. Flint that has been carried by a glacier is subject to frost fracture and internal flaws. However, material collected as beach pebbles can be even poorer quality through repeated percussion against other pebbles, leading to frequent internal flaws. Sometimes till material was tested, probably at source, by the removal of a flake; other times it was not, resulting in the importing of material to Lake Flixton that was sometimes unusable. The sea would have been in the order of 10-20 km distant, and with no obvious navigable water course between the sea and Lake Flixton to aid transportation of heavy flint nodules. This could suggest that the people that procured the flint were not its users: it may have been obtained through exchange with another group, or perhaps by less-experienced group members, such as children.

Several raw-material caches have been found in the Vale of Pickering (see Conneller and Schadla-Hall 2003), including two in the current excavations at Star Carr. Apart from a single nodule of Wolds flint from the Seamer D cache, all remaining 45 nodules recovered from caches were till flint, indicating the preferential establishment of caches of non-local high-quality till flint in the landscape. These caches consist of flint nodules that have undergone various levels of reduction. The caches from Flixton School (Conneller and Schadla-Hall 2003) and from the Star Carr western platform consist of large nodules, mostly with only a few flakes removed to test for quality. Other caches have seen greater levels of reduction: the AC8 cache found on the wetland edge at Star Carr (Figure 8.43) consists of 19 pieces, most of which seem to derive from a single large nodule which has been split. Almost all pieces in this cache have seen some level of reduction, usually the neat removal of a small number of blades (up to 12 removals, though most have fewer). A cache from Seamer D (Conneller and Schadla-Hall 2003) is very similar, though in this case small to medium-sized beach pebbles have been reduced by the removal of a number of blades. Caches also vary in size from two nodules in the Star Carr western platform cache (Figure 8.30), to 19 pieces in the AC8 cache.

The opaque white or grey Wolds flint is potentially a much more local source as the scarp slope of the Yorkshire Wolds forms the southern boundary of the Vale. But despite its proximity, Wolds flint was less frequently employed in Early Mesolithic assemblages. The chalk plateau of the Wolds is made up of five different 
formations: the Flamborough, Burnham, Welton, Ferriby and the Rowe Chalk formations (Hopson 2005). While only $35 \%$ of the chalk contains flint, most of the flint-less Flamborough formation remains unexposed. However, both the Burnham and Welton formations contain a number of siliciferous horizons, the Welton Formation containing nodular flint, and the Burnham Formation mainly tabular and semi-tabular flint (Wood and Smith 1978; Henson 1982; Hopson 2005). Exposures of these horizons are likely to have existed through erosion of the Wolds edge. However, Wolds raw material in the present day, whether occurring as isolated examples eroded from the chalk or as a number of flint horizons exposed through quarrying, is rarely of knappable quality, being brittle and usually frost fractured. Mining for unaffected flint was not an option, even in the Neolithic, because Wolds chalk, unlike the chalk of southern England, is very hard. One mechanism for obtaining undamaged Wolds material may have been through the erosional action of the numerous springs and streams which originated on the Wolds edge and drained into Lake Flixton. Here, nodules would have been less subject to the extremes of temperature variation that results in frost fracturing. Large cobbles have been recovered from ancient stream beds elsewhere in the Vale (Zylawyj 1986).

Wolds flint occurs both in nodular and tabular forms, the nodular form being of higher knapping quality, while the tabular form has a tendency to fracture along its natural planes. Durden (1995) suggests that although tabular chalk flint is too brittle for knapping, the nodular type is rather more suitable and was used in Mesolithic industries and for small and simple tools in later periods. While this appears true of some Mesolithic industries (certain Pennine assemblages, for example, appear to be manufactured entirely on nodular Wolds flint: see Chapter 11) during both the Late Palaeolithic and Early Mesolithic periods in the Vale of Pickering tabular material appears to have been utilised as well as nodular Wolds flint.

In comparison to till flint, Wolds material varies relatively little in colour, ranging from opaque bluish grey or grey to white. It is coarser and of much poorer quality than till flint and contains numerous flaws, pinholes and fossils. It is thus more difficult to work and is generally much less abundant in archaeological assemblages in the Vale of Pickering.

Rarer still is chert, which is found only as occasional flakes, and in one instance a core. Only 22 pieces were recovered from the entire site. Two pieces of banded chert may derive from the Yorkshire Dales or Northumberland (Stephen Poole pers. comm.). Where present this chert has a beach pebble cortex suggesting it was obtained in the same way as till flint. While till flint was imported to the Pennines during the Early Mesolithic in large quantities, chert from the Pennines does not seem to have made the journey in reverse (Chapter 11).

Overall at Star Carr, till material outnumbers Wolds flint at a ratio of 4.84:1. An examination of raw material ratios in well-dated areas of the site suggests there does not appear to be any patterning to raw-material choices over time (see Table 35.3).

More striking is the difference in the use of different materials for different tools (Table 35.4). Overall 82.7\% of the assemblage was made from till material. In general there was a preference to manufacture tools from till flint, in particular microliths, of which $94.2 \%$ were made from this material. The manufacture of awls also shows a strong preference for till, suggesting it was widely viewed as the most appropriate material for manufacturing sharp points. Conversely axes were produced on Wolds material and till material in equal numbers. This may be because Wolds material could be obtained both in fairly large packages and in the flat tabular or semi-tabular form that appears to have been favoured for the axe manufacture. However, there are also other possibilities: axes appear to have been curated tools so may have circulated through exchange mechanisms. Alternatively, as curated objects they may reflect longer-term mobility and embedded procurement patterns than more expedient tools.

\begin{tabular}{|c|c|c|c|c|c|c|}
\hline & c. $9300-9000$ cal BC & c. 8950 cal BC & c. 8850 cal BC & c. 8800 cal BC & c. 8700 cal BC & c. $8500 \mathrm{cal} \mathrm{BC}$ \\
\hline & Detrital wood & Central platform & Axe workshop & Clark's area & SC22 scatter & Fen scatter \\
\hline Till flint & 88.3 & 84.4 & 78.2 & 86 & 93.2 & 86.2 \\
\hline Wolds & 11.7 & 15.6 & 21.5 & 14 & 6.8 & 13.5 \\
\hline Chert & 0 & 0 & 0.3 & 0 & 0 & 0.3 \\
\hline
\end{tabular}

Table 35.3: Use of different flint sources in well-dated areas of the site. 
Till flint in particular is available in a range of different colours. Sampling of material currently available as beach pebbles shows speckled grey flint is the most common, with smaller quantities of brown, red, black and white and grey flint. Wolds flint is less diverse, varying from opaque white to grey specked opaque or semi-translucent, the latter type overlapping with the appearance of till flint. The representation of different colours in the assemblage broadly follows that currently available (Table 35.5), though brown flint is probably better represented. This may be a result of contemporary differences in coastal geomorphology; however, brown flint is in general of higher quality than grey flint, suggesting possibly some selection for quality.

Tools show some variation in choice of colour, though is probably a result of choices related to quality, size or source of material. Axes, for example, show greater use of grey flint, which is related to greater use of Wolds flint (see Table 35.6), for reasons described above. Microliths were much more likely to be made from brown flint, presumably because this is of higher quality and more aerodynamic. The shift to the use of small geometric

\begin{tabular}{|l|r|r|}
\hline Tool type & \multicolumn{1}{|l|}{ Till \% } & Wolds \% \\
\hline Awl & 90 & 10 \\
\hline Axe & 50 & 50 \\
\hline Burin & 71.5 & 28.5 \\
\hline Microlith & 94.2 & 5.8 \\
\hline Scraper & 87.5 & 12.5 \\
\hline
\end{tabular}

Table 35.4: Use of different materials for production of different tool types.

\begin{tabular}{|l|r|}
\hline Flint colour & \multicolumn{1}{|l|}{$\%$} \\
\hline grey & 58.7 \\
\hline brown & 32.2 \\
\hline black & 3.8 \\
\hline red & 1.9 \\
\hline white & 2.8 \\
\hline white and grey & 0.6 \\
\hline
\end{tabular}

Table 35.5: Use of flint of different colours.

\begin{tabular}{|l|r|r|r|l|r|r|}
\hline Tool type & grey & brown & black & \multicolumn{1}{l|}{ red } & white & white and grey \\
\hline Awl & 72.2 & 26 & 1.8 & 0 & 0 & 0 \\
\hline Axe & 83.4 & 16.6 & 0 & 0 & 0 & 0 \\
\hline Burin & 67.9 & 18.8 & 6.1 & 5.5 & 1.6 & 0 \\
\hline Microlith & 47.7 & 46.7 & 4.7 & 0.9 & 0 & 0 \\
\hline Scraper & 61.6 & 28.3 & 5 & 2.7 & 0.9 & 1.4 \\
\hline
\end{tabular}

Table 35.6: Use of flint of different colours in the manufacture of different tools. 
microliths in the Late Mesolithic has been interpreted as facilitating use of local poor-quality sources (Myers 1989), and this finding is reinforced by the association of microliths with the highest-quality flint in the Early Mesolithic.

\section{Technology}

The use of small, often flawed beach pebbles as the predominant flint source constrained the possibilities for the types of reduction sequences employed. The most common methods of reduction for small beach pebbles involved the removal of a single cortical flake to create a platform and then use of any natural ridge the pebble provided to initiate blade production. If such a ridge was not present cresting was sometimes employed. The initial decortication often took place using a hard hammer, while a soft hammer was routinely employed during plein debitage.

Refitting of longer sequences of better-quality material indicates the use of one preferential platform (contra Reynier 2005, 49), with a second platform primarily used to correct mistakes (Figure 8.22). This secondary platform was usually an opposed platform, at $180^{\circ}$ to the primary platform, though platforms both perpendicular and at an acute angle to the primary platform were occasionally employed. The use of beach pebbles often containing imperfections necessitated flexibility, and a platform was often completely abandoned due to the presence of a flaw, sometimes generating multiple platforms. Several such sequences have been refitted (see Figures 8.8 and 8.21). Poorer-quality material was less productive; fewer products of such sequences were removed for use elsewhere, so it is likely that there has been greater success refitting these poor-quality nodules.

Refitting indicates that the dynamic nature of reduction sequences is not always reflected in the abandoned core, with the presence of secondary platforms both erased by later removals, or opposed platforms present in a discarded core that refitting indicates has been minimally used. Information present in abandoned cores (Table 35.7) indicates a predominance of single platform cores, reduced part of the way round (usually with a cortical back). Opposed platform cores are nearly as common, with other types rarer. Cores made on flakes (that look similar to burins) are present but very rare. The representation of core types is very similar to that reported by Reynier $(2005,32)$ for the Star Carr type-site of Pointed Stone on the North York Moors, though multiplatform cores are less common at Pointed Stone, perhaps because people relied on better-quality material for journeys to the uplands.

Cores range in height from 20 to $77 \mathrm{~mm}$ with an average of $40 \mathrm{~mm}$, in width from 17 to $71 \mathrm{~mm}$ with an average of $35 \mathrm{~mm}$ and a thickness from 3 to $77 \mathrm{~mm}$ with an average of $26 \mathrm{~mm}$ (Figure 35.1). Almost all the cores above $60 \mathrm{~mm}$ in height appear to be from caches. Six of the 13 cores in this size range derive from the AC8 cache, and a further three were recorded from test pit SC6, from an area of less than $1 \mathrm{~m}^{2}$, possibly representing a second cache. Core thickness also correlates with cached material, with four of the 10 thickest cores coming from the AC8 cache. Core thickness has a very steep drop-off below $15 \mathrm{~mm}$, indicating that beyond this thickness cores became difficult to work.

Platform/core face angles were maintained through removals of core tablets. Faceting was not used. Butts are usually plain and linear, sometimes punctiform. Re-cresting may occasionally have been employed mid-sequence

\begin{tabular}{|l|r|}
\hline Core types & \multicolumn{1}{|c|}{$\%$} \\
\hline A1: Single platform, reduced round entire circumference & 4.0 \\
\hline A2: Single platform reduced part way round & 34.1 \\
\hline B1: Opposed platform core & 27.5 \\
\hline B2: Two platforms, with one at oblique angle & 6.6 \\
\hline B3: Two platforms, with one at right angles & 4.4 \\
\hline C: Multi-platform core & 11.4 \\
\hline D: Core reduced either side of a ridge & 5.5 \\
\hline E: As D, but multi-platform & 6.6 \\
\hline
\end{tabular}

Table 35.7: Core types represented. 


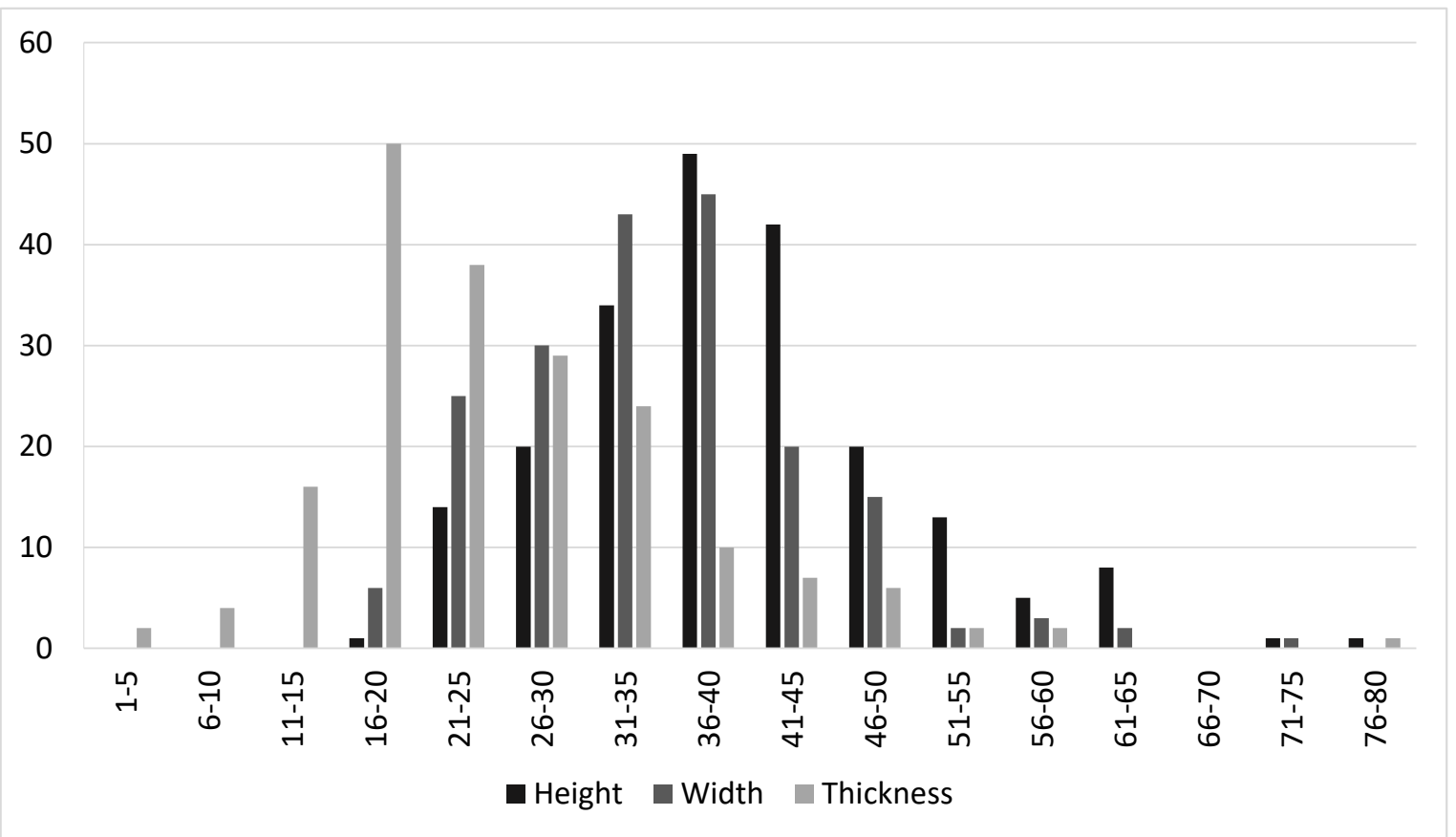

Figure 35.1: Core dimensions (mm) (Copyright Star Carr Project, CC BY-NC 4.0).

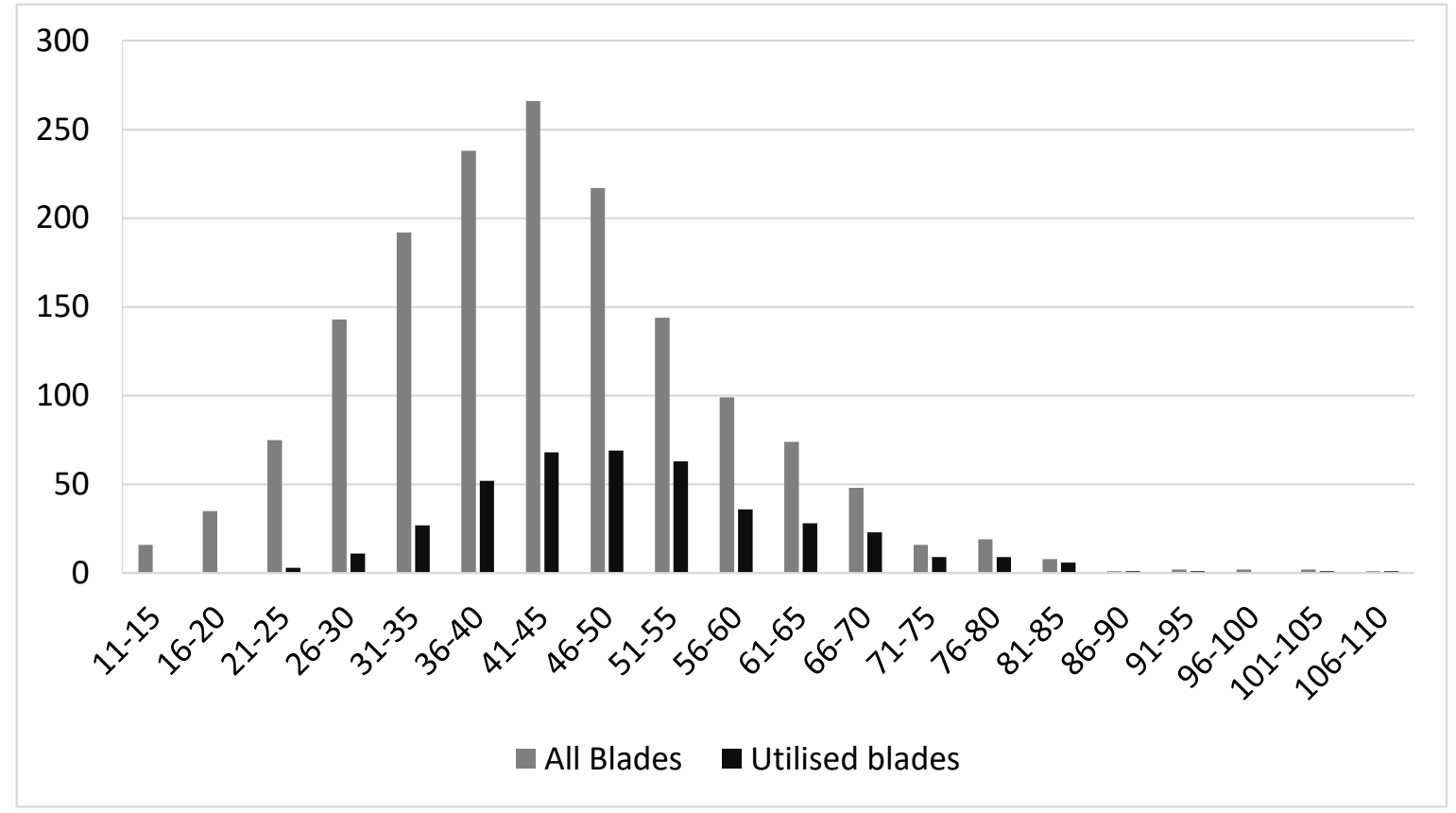

Figure 35.2: Length of all blades (including utilised blades) and length of utilised blades ( $\mathrm{mm}$ ) (Copyright Star Carr Project, CC BY-NC 4.0). 


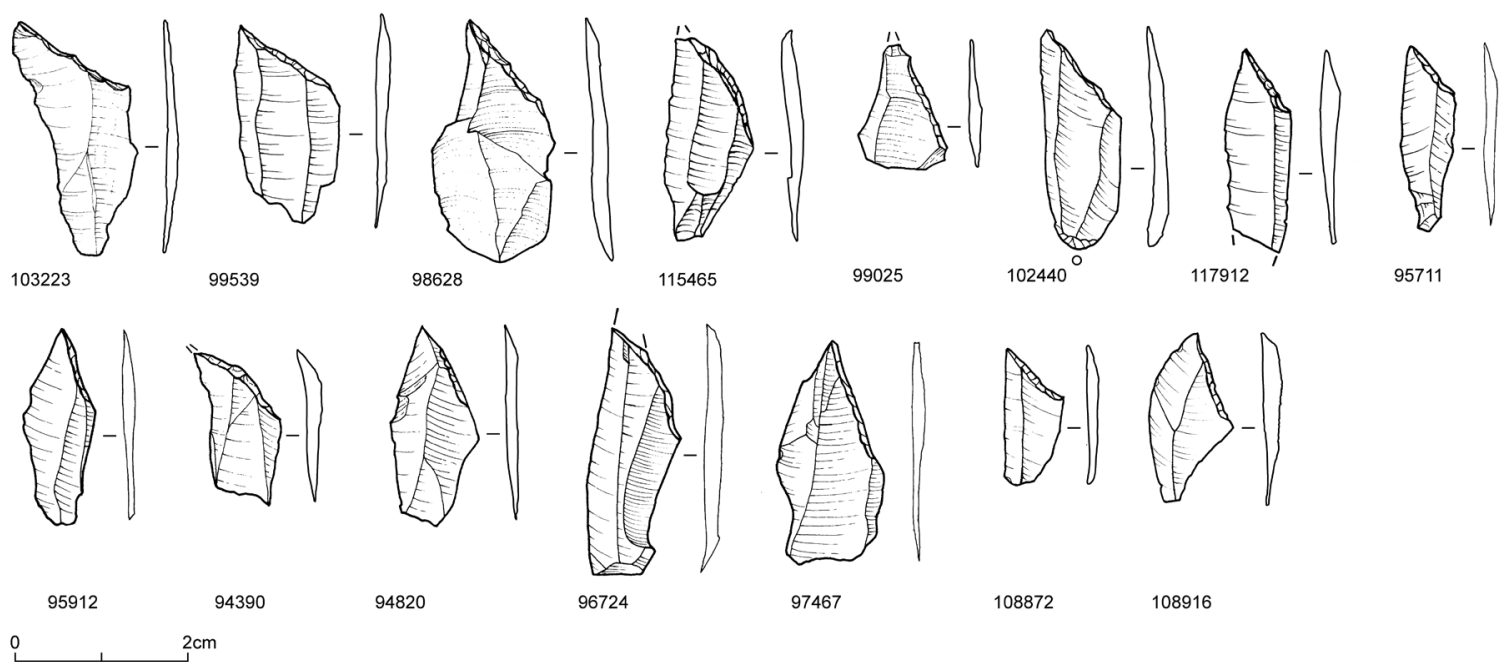

Figure 35.3: Right lateralised obliquely blunted points (Copyright Craig Williams, CC BY-NC 4.0).

to reshape the core; however, in general knappers created a new platform if problems were encountered. If this was perpendicular to the original platform, the original platform/core face was used to guide the first removal. This produced a blank morphologically similar to a crested blade (though the cresting is unilateral).

Debitage was focused on the production of bladelets and narrow flakes, though some larger blades were also produced. Blade/let sizes range up to $110 \mathrm{~mm}$ in length (thus overlapping with lengths displayed by Long Blade assemblages in the region), with an average of $42 \mathrm{~mm}$. The larger blades were more likely to have been defined as utilised (displaying macroscopic damage), whilst only a small proportion of blades less than $50 \mathrm{~mm}$ show evidence of use (Figure 35.2). Of blades between 51 and $65 \mathrm{~mm}$, around one third shows evidence of use, while the figure rises to around $50 \%$ for pieces between 66 and $80 \mathrm{~mm}$. Of the 16 longest pieces $(>80 \mathrm{~mm}), 10$ show evidence for macroscopic damage, indicating that the larger pieces were specially manufactured for use (with the two pieces above $80 \mathrm{~mm}$ that were analysed for microwear having been used on hard materials, bone and antler). Blades above $80 \mathrm{~mm}$ are also more likely to have been made out of Wolds than till material.

Dumont carried out microwear analysis of five cores which he classified as core scrapers. On four of these he observed stone on stone traces consisting of crushing and striae, but believed this to be the result of indeterminate use, not a by-product of technology. As part of this study, we also analysed three cores. One was classified as a denticulate core and so is discussed in that section below. The remaining two consist of an A2 blade core and a type E disc core. The latter was part of the AC8 cache and was used for a short duration of time to scrape wood. The blade core $<98992>$ displayed no visible signs of use. Two core tablets were also analysed and have very ephemeral traces suggesting a very short duration of use: $\langle 98985>$ was probably used to scrape a soft animal material, probably hide, and $<107985>$ was used to scrape an indeterminate material prior to burning.

\section{Tools}

\section{Microliths}

Microliths, the type fossil of the Mesolithic, are well represented at Star Carr, with 313 examples. With a few exceptions, all are classic 'Star Carr' Early Mesolithic types (Radley and Mellars 1964; Reynier 2005), consisting of obliquely blunted points, trapezes and large isosceles and scalene triangles (Figures 35.3-35.4 and 35.6-35.8). Of these, obliquely blunted points are by far the best represented (Table 35.8). In contrast to later Early Mesolithic assemblages (Deepcar and basally modified assemblage types, see Chapter 11), points lateralised to the 

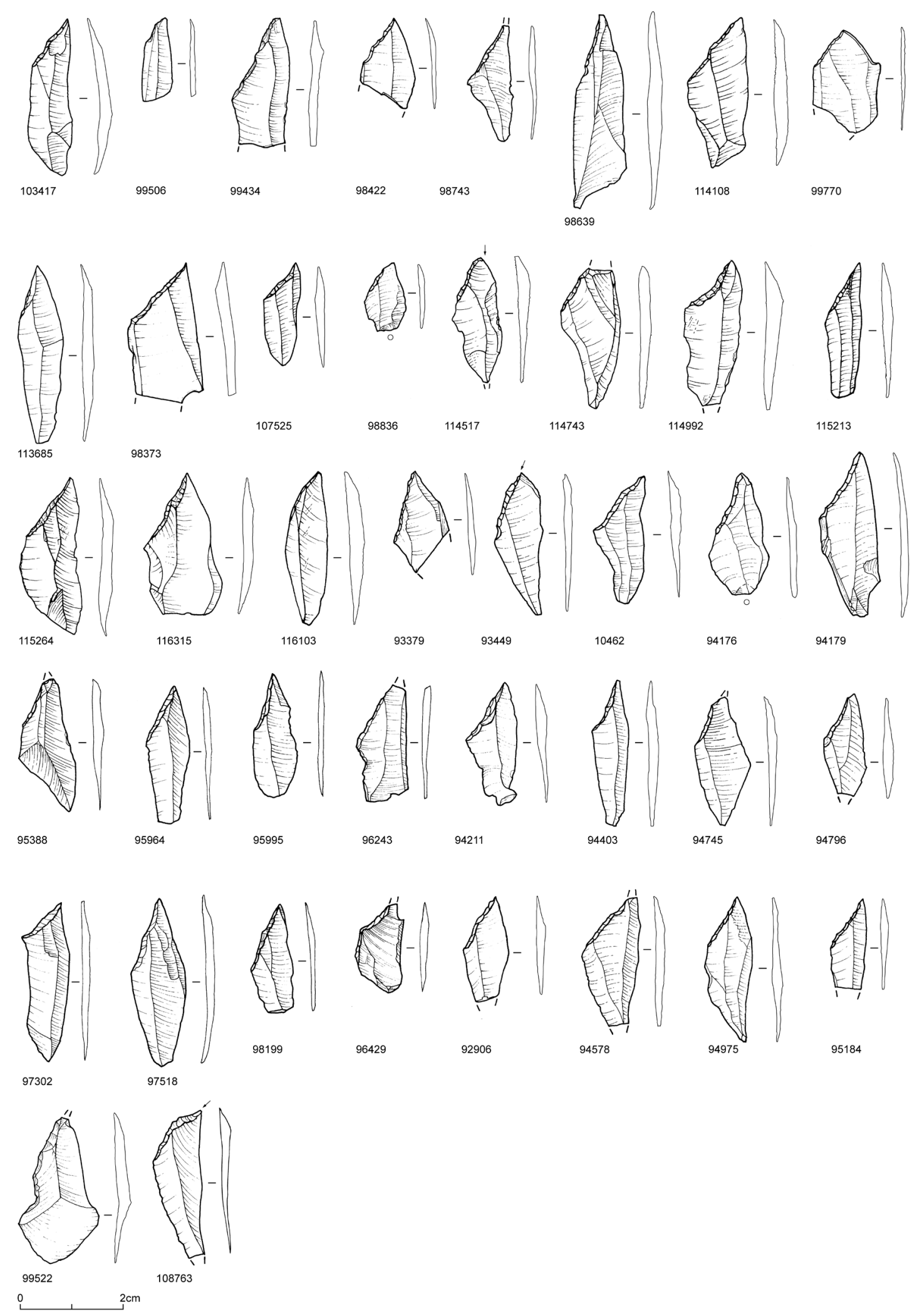

Figure 35.4: Left lateralised obliquely blunted points (Copyright Craig Williams, CC BY-NC 4.0). 

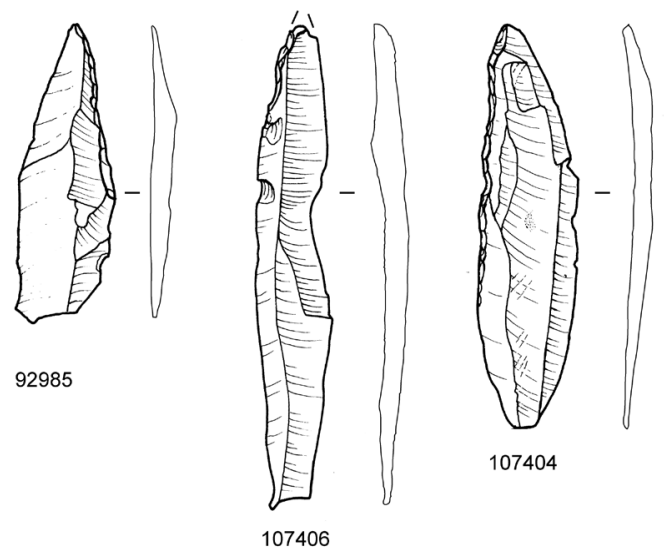

0 $2 \mathrm{~cm}$

Figure 35.5: Partially backed points (Copyright Craig Williams, CC BY-NC 4.0).
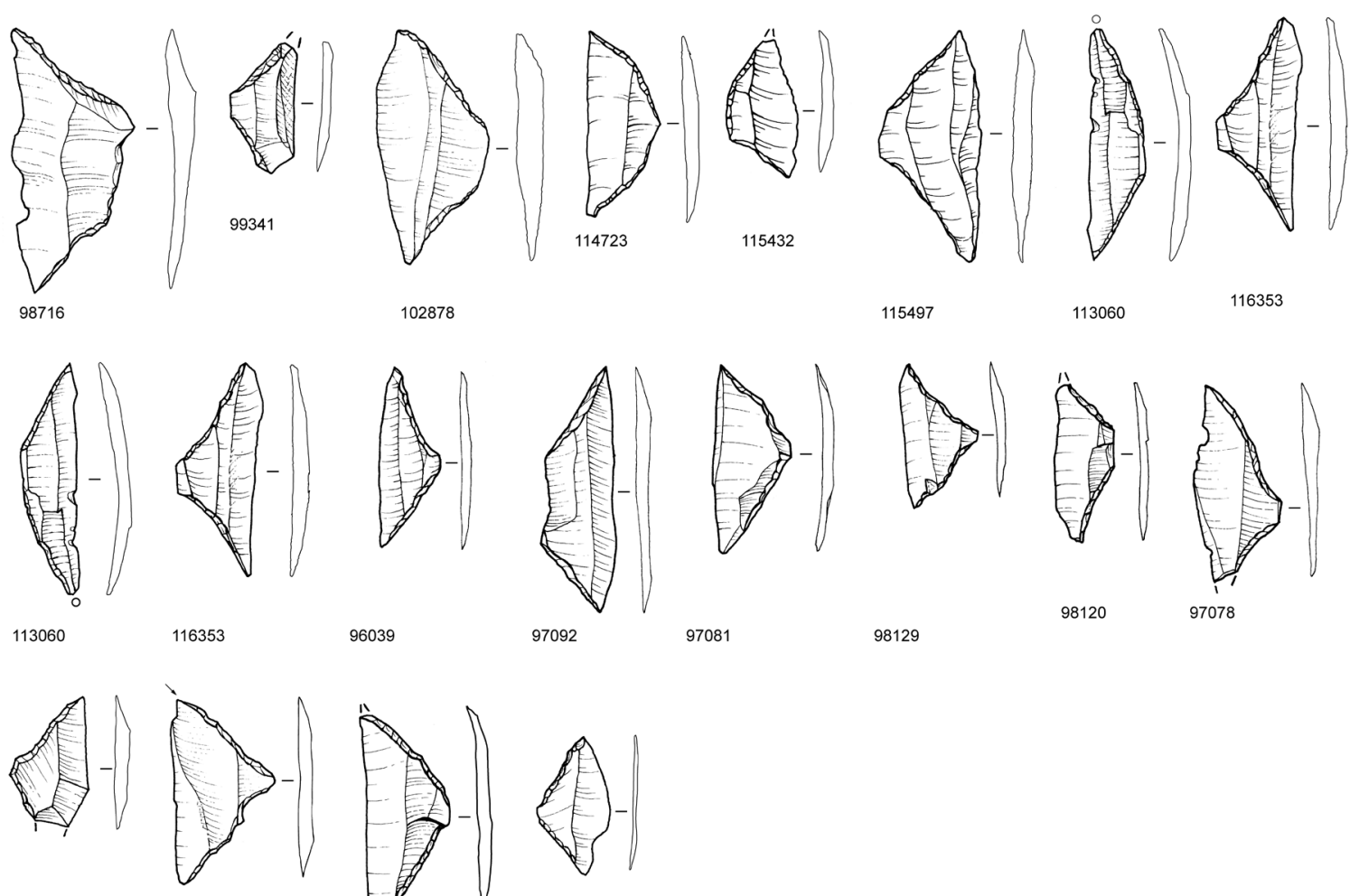

99579
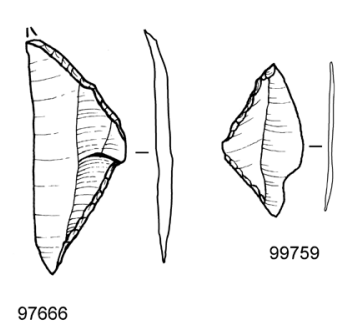

0 $2 \mathrm{~cm}$

Figure 35.6: Trapezes (Copyright Craig Williams, CC BY-NC 4.0). 


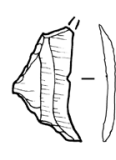

102742
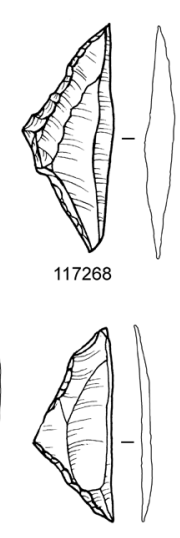

98675

103240

0

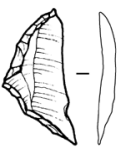
$2 \mathrm{~cm}$

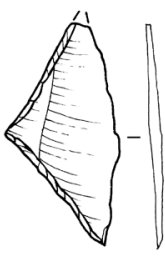

96227

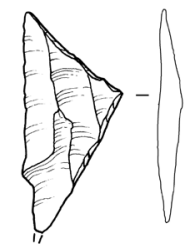

102854

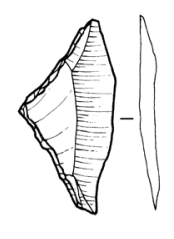

96787

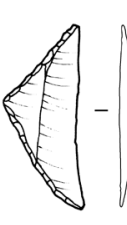

102776

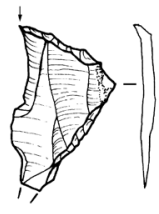

97753

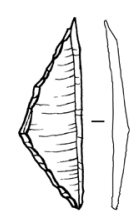

114570
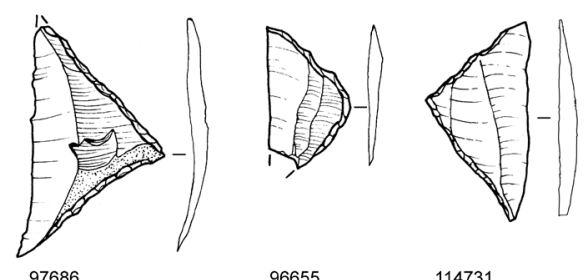

114731

Figure 35.7: Isosceles triangles (Copyright Craig Williams, CC BY-NC 4.0).
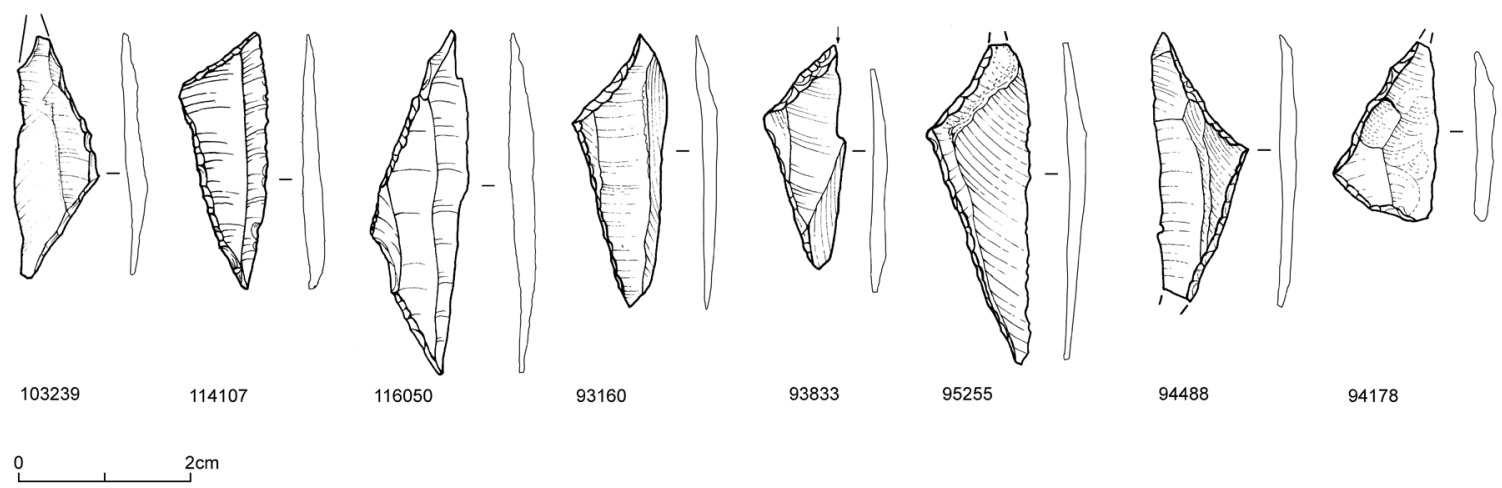

Figure 35.8: Large scalene triangles (Copyright Craig Williams, CC BY-NC 4.0).

\begin{tabular}{|l|r|}
\hline Type & No. \\
\hline Obliquely blunted point & 180 \\
\hline Partially backed & 8 \\
\hline Trapeze & 39 \\
\hline Isosceles triangle & 15 \\
\hline Large scalene & 31 \\
\hline Rhomboid & 2 \\
\hline Small scalene & 4 \\
\hline Narrow backed bladelet & 1 \\
\hline Microlith/awl & 3 \\
\hline Unfinished & 4 \\
\hline Unidentifiable fragment & 26 \\
\hline Total & 313 \\
\hline
\end{tabular}

Table 35.8: Microlith forms represented in the assemblage. 
right are present in large numbers (Figure 35.3), though left lateralisation is more common overall (Figure 35.4). Eight partially-backed points were recovered, some of which have retouch extending relatively far down the margin (Figure 35.5). These, and rhomboids, which were also found in small numbers, are more indicative of 'Deepcar' type assemblages (Radley and Mellars 1964; Reynier 2005) that seem to appear slightly later than Star Carr type assemblages (Conneller and Higham 2015, Conneller et al. 2016). It is difficult to know whether these few pieces can simply be encompassed within the range of variation of a large assemblage of Star Carr types. None were found in Reynier's (2005) survey of Star Carr assemblages, though he only looked at three small sites with a total number of 87 microliths. Functional differences are also a possibility: two partially backed examples were examined for microwear and both were used as barbs of projectiles. However, two microliths of this same type, found only $4 \mathrm{~m}$ apart in the wetland, date from one of the latest phases of the site (the others come from dryland contexts and cannot be dated), suggesting chronological factors could be an issue. The area they were recovered from has a TPQ of 8670-8475 cal BC (95\% probability; TPQ fen flint; Figure 17.9), probably in or after $8605-8515 \mathrm{cal} \mathrm{BC}(68 \%$ probability). This suggests that changes in microlith forms may have occurred during the time the site was occupied.

Two likely composite tools were recovered. One of these consists of three obliquely blunted points, all lateralised to the right. Two, $<103421>$ and $<103390>$, are relatively narrow and of very similar dimensions $(27 \times 8 \times$ $1 \mathrm{~mm}$ and $26 \times 7 \times 2 \mathrm{~mm})$, the other, $<103392>$ is shorter and squatter $(21 \times 9 \times 2 \mathrm{~mm})$ (Figure 35.9). All have soft animal traces, which are most developed on $<103392>$ which has longitudinal traces along one lateral, possibly of meat, and hafting traces on the other. The soft animal traces are also well developed on the tip of $<103421>$, suggesting it served as the tip or point of the composite tool, a function to which it is also morphologically suited. The microliths were recovered in a broadly linear arrangement, with $50 \mathrm{~mm}$ separating $<103392>$ and $<103390\rangle$ and a further $150 \mathrm{~mm}$ separating these from $<103421\rangle$. $<103390\rangle$ and $<103392\rangle$ were found at the same time. It was noted on excavation that these were microliths from a wetland context, so particular attention was paid to the search for an arrow shaft, but none was found. Barbed points appear to have been dehafted before deposition into the wetland (see Chapter 25), and the same may have been true of flint projectiles.

A second composite tool was found on the dryland. This also lacks a haft, but here preservational issues are likely to be responsible. The microliths were also slightly dispersed, suggesting some post-depositional disturbance (see Figures 35.10 and 8.45). The composite consists of four small narrow, elongated scalene triangles with two sides retouched, which are likely to have acted as barbs and a narrow backed bladelet, likely to have acted as the tip. This is thus a Late Mesolithic composite, a rare instance of later visits to the area after the main phase of occupation of Star Carr had ceased. These microliths are very similar in size and type to the second composite grouping recovered from Seamer K (David 1998); however, the exact shape of the scalenes represented is slightly different. Barton and colleagues $(1991,102)$ make a distinction between scalene triangles and narrow backed bladelets with a slightly oblique truncation to describe the differences between discoveries of potential composites at Waun Fignen Felen 1 and 9. The Star Carr composite better approximates the latter. A second difference is the number of microliths represented. The two Seamer composites have 16 and 17 pieces respectively, the Star Carr example only five. This might suggest variation in form; alternatively this one may have snapped and only part of the composite discarded here. All pieces were examined for microwear. Three
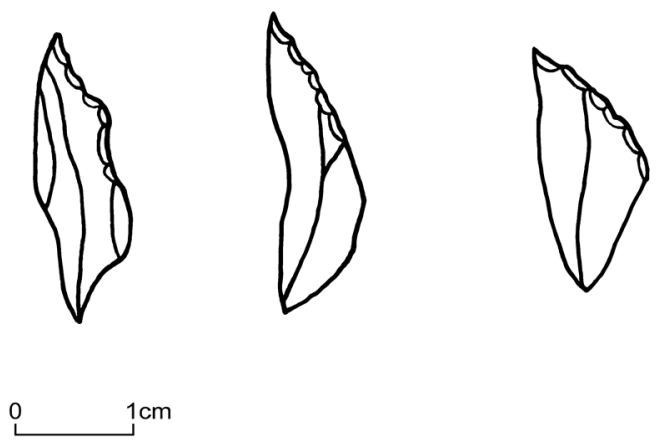

Figure 35.9: Early Mesolithic microliths from probable composite tool. From left to right: $<103421>,<103390>$ and $<103392>$ (Copyright Star Carr Project, CC BY-NC 4.0). 


\section{0}
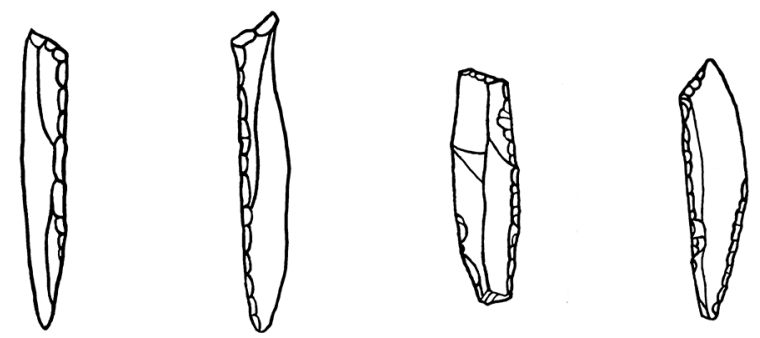

$\quad 1 \mathrm{~cm}$

Figure 35.10: Late Mesolithic microliths from composite projectile. From left to right: $<110656>,<110657>$, $<110660>,<110658>,<110659>$ (Copyright Star Carr Project, CC BY-NC 4.0).

\begin{tabular}{|c|c|c|c|c|c|c|}
\hline & $\begin{array}{l}\text { c. } 9300- \\
9000 \text { cal BC }\end{array}$ & $\begin{array}{l}\text { c.8950 } \\
\text { cal BC } \\
\end{array}$ & $\begin{array}{l}\text { c.8850 cal } \\
\text { BC }\end{array}$ & c. $8800 \mathrm{cal} \mathrm{BC}$ & $\begin{array}{l}\text { c.8700 cal } \\
\text { BC }\end{array}$ & $\begin{array}{l}\text { TPQ c.8500 } \\
\text { cal BC }\end{array}$ \\
\hline Microlith type & Detrital wood & $\begin{array}{l}\text { Central } \\
\text { platform }\end{array}$ & $\begin{array}{l}\text { Axe } \\
\text { workshop }\end{array}$ & Clark's area & SC22 scatter & Fen scatter \\
\hline Obliquely blunted point & 4 & 3 & 1 & 3 & 0 & 0 \\
\hline Small obp $<25 \mathrm{~mm}$ & 1 & 0 & 4 & 0 & 1 & 0 \\
\hline Trapeze & 0 & 0 & 3 & 0 & 0 & 0 \\
\hline $\begin{array}{l}\text { Trapeze/triangle with } \\
\text { concave truncation }\end{array}$ & 0 & 0 & 0 & 2 & 0 & 0 \\
\hline Isosceles triangle & 0 & 1 & 1 & 2 & 0 & 0 \\
\hline Large scalene triangle & 0 & 0 & 0 & 0 & 0 & 1 \\
\hline Partially backed & 0 & 0 & 0 & 0 & 1 & 2 \\
\hline Average length of obp (mm) & 26.6 & 29 & 19.6 & 28.7 & 26.5 & $\mathrm{n} / \mathrm{a}$ \\
\hline
\end{tabular}

Table 35.9: Representation of microlith forms in well dated areas of the site.

had no obvious traces, but one $<110658>$ had impact damage and another $<110657>$ had longitudinal meat traces, suggesting it had been used as a projectile.

In order to understand whether there was temporal variation in microlith form within Star Carr type assemblages, microliths in well-dated areas of the site underwent more detailed typological scrutiny (Table 35.9). These well-dated areas are inevitably wetlands, where unfortunately microliths were relatively uncommon, so any potential patterns are extremely tentative. Broadly, there appears to be an increase in diversity over the c. 800 years during which Star Carr was visited, with microliths from the earliest area, the detrital wood scatter, consisting only of obliquely blunted points. After $9000 \mathrm{cal}$ BC diversity increases with the presence of triangles and trapezes. Though this pattern is tentative, a similar sequence does seem to be present in Southern Scandinavia and Northern Germany (Chapter 12). Partially backed pieces, as described above, are present only in the latest contexts of the site. Concave truncations, which do seem to have some chronological component when found on obliquely blunted points (e.g. Lewis and Rackham 2011), are only here associated with triangles and trapezes, and are too few to show any chronological significance. There is some evidence to suggest that obliquely blunted points became smaller over the course of the Mesolithic (Pitts and Jacobi 1979). However, this diminution does not appear to have commenced over the period of time represented by the site. The small 
size of the microliths from the axe workshop should be noted, but these are perhaps due to personal choice or the particular raw materials available for what may have been a short-term event.

In total, 24 microliths were analysed for wear traces (Table 35.10). Of these, six displayed MLITS (micro longitudinal impact traces) and therefore can be confidently said to have been used as projectiles (Figure 35.11). Of these four (three obliquely blunted points and a trapeze) were hafted as points, two (both partially backed points) as barbs. A further six examples could have been used as projectiles, but may have had alternative uses. In addition, one microlith has possible impact traces and three have traces resulting from soft animal material (hide and/or meat) and thus may either have been used as projectiles (though display no MLITS) or composite knives (see discussion above). Another, <94728> has very clear longitudinal meat traces along one edge and was either hafted and used as a barb of a projectile or a knife, whilst $<107673\rangle$ displayed fresh hide damage at the tip but no impact damage, making it difficult to determine whether it functioned as a projectile or was perhaps hafted as a knife.

Other microliths can be more confidently attributed a non-projectile function: one microlith, $<95813>$ has both hide and mineral traces and was used to scrape and pierce, suggesting it was used as a craft tool. Another, $<113623>$, had bone traces resulting from both cutting and scraping. Interestingly, two microliths, <108736> and $<110059>$, display plant-working traces (one was used for cutting, another for scraping and/or peeling). However, the presence of plant-working traces on microliths is not unusual; such an association is known from other Northwest European Early Mesolithic sites, for example, at Verrebroek, Belgium (Crombé et al. 2001), and Yangtze Harbour, the Netherlands (Sier et al. 2014). Given the clustering of microliths in and around structures and in association with hearth features, which is interpreted as the result of re-tooling episodes as well as the utilisation of microliths in craft work, it is perhaps unsurprising that just three microliths displayed no wear traces at all, with the vast majority representing utilised tools.

However, what is intriguing is how our analyses of microlith function(s) differs from that of Dumont, who identified just one piece (an obliquely blunted point) with wear traces out of the 31 he analysed. The point displayed bone polish along one lateral edge. This, he concluded, could have resulted from impact with bone or from being hafted longitudinally in a bone haft. However, if the latter were the case, adhesive would have been required, resulting in little to no development of polish. As such, the reason for this discrepancy is not clear. One possibility is that Dumont, reflecting common belief at that time, which saw microliths as functioning solely as projectiles, focused on evidence for impact only, potentially missing traces resulting from their various other uses, such as composite knives, hide and plant-working tools. However, the thoroughness of his analyses, covering all parts of the tool's surface, makes it difficult to see how he would have missed impact and non-impact related traces if/when present.

\begin{tabular}{|l|l|l|r|}
\hline Primary contact material & Secondary contact material & Action & No. \\
\hline Impact & Impact/plant (1) & Projectile & 6 \\
\hline Impact? & & Projectile? & 1 \\
\hline Indet. & & Cutting (1), Indet. (3) & 4 \\
\hline Animal soft & & Indet. (2), Cutting (1) & 3 \\
\hline Animal various & & Butchery & 1 \\
\hline Plant & Siliceous plant (1) & Cutting & 1 \\
\hline Hide & Mineral (1) & Scrape/pierce, piercing & 2 \\
\hline Meat & & Projectile/knife? & 1 \\
\hline Bone & & Cutting/scraping & 1 \\
\hline Not used & & n/a & 3 \\
\hline Un-analysable & & n/a & 1 \\
\hline Total & & & 24 \\
\hline
\end{tabular}

Table 35.10: Microwear results for microliths. 


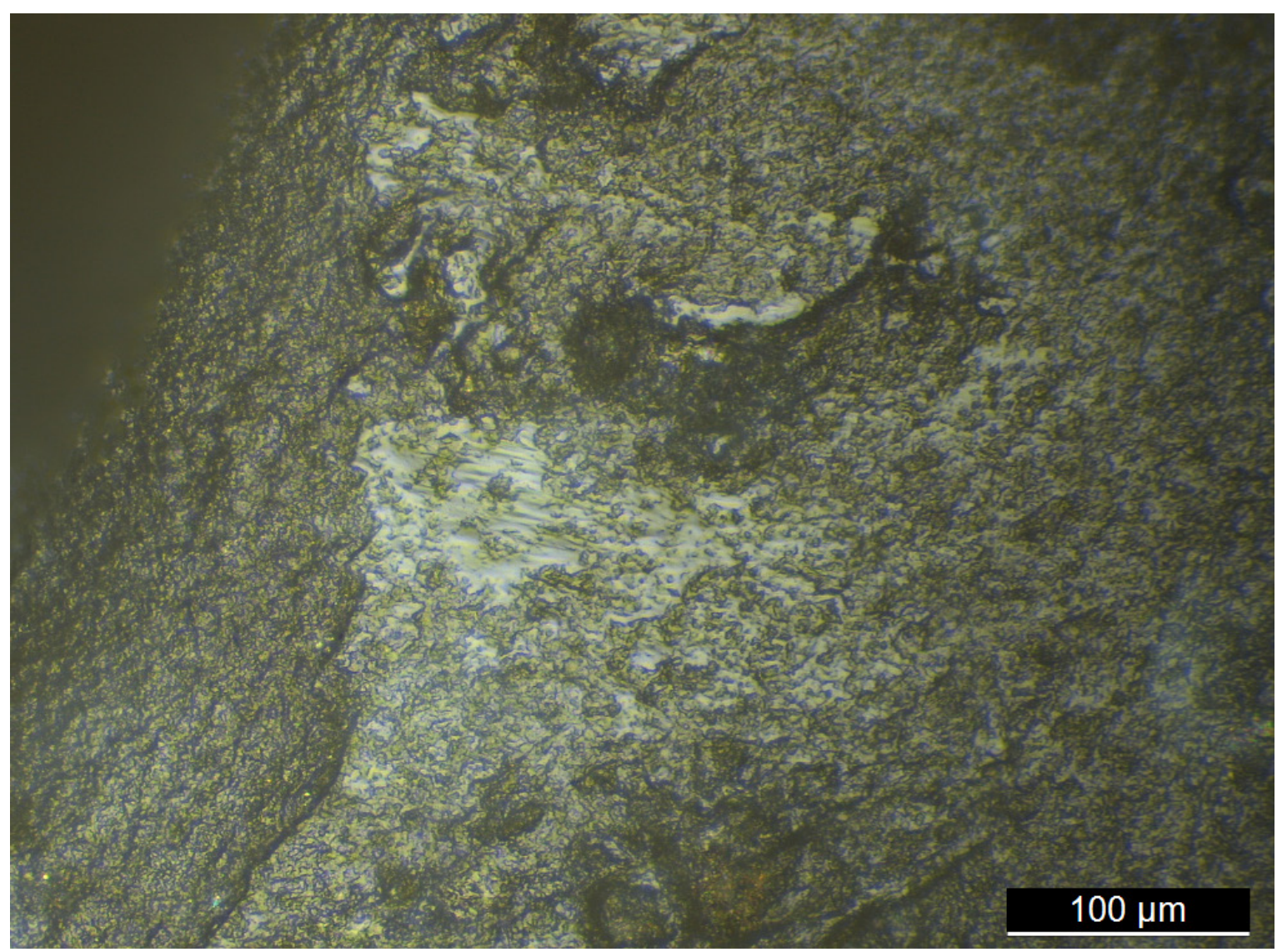

Figure 35.11: Micro longitudinal impact traces and impact fracture on microlith $<95542>(\times 20$ magnification) (Copyright Aimée Little, CC BY-NC 4.0).

Microliths and their manufacturing debris, microburins, have a strong association with hearths, structures (except the central structure) and the areas immediately surrounding structures (Figure 35.12). The association with hearths is understandable given that microliths are composite tools that would have needed mastic to haft them. These composites would be made and repaired around hearths, and redundant components seem to have been discarded in the immediate area. Microliths are also common in some wetland edge areas, mainly the axe workshop and the bead area, though here microburins are less common, indicating areas of tool use and discard rather than manufacture. They are less common in wetland areas where they are likely to represent lost composites or material involved in depositionary practices.

Axes

Twenty axes were recovered, plus two further probable axes that had been reworked as cores. This is a large number for an Early Mesolithic site, where axes are generally found in relatively low quantities. Axes vary in their morphology, from fine ovate or elongated forms to triangular sectioned (Figures 35.13 and 35.14, see also Figure 8.38) and small irregular examples. A tapered, pointed or triangular butt is a feature of some (see for example Figures 35.14 and $8.38,<99454>$ ), while others seem to have seen use at both ends (Figure 8.38, $<94367>$ ). This variation in form is likely to be due to raw-material constraints (in an area of relatively small and often poor-quality material) and resharpening practices. Axes are found at most stages of their life histories from a large preform $230 \mathrm{~mm}$ (Figure 35.15) in length to small, exhausted pieces at c. $50 \mathrm{~mm}$ in length. However, most are relatively small. The average of complete, finished forms is $66.7 \times 33.8 \times 20.5 \mathrm{~mm}$. Several refit 


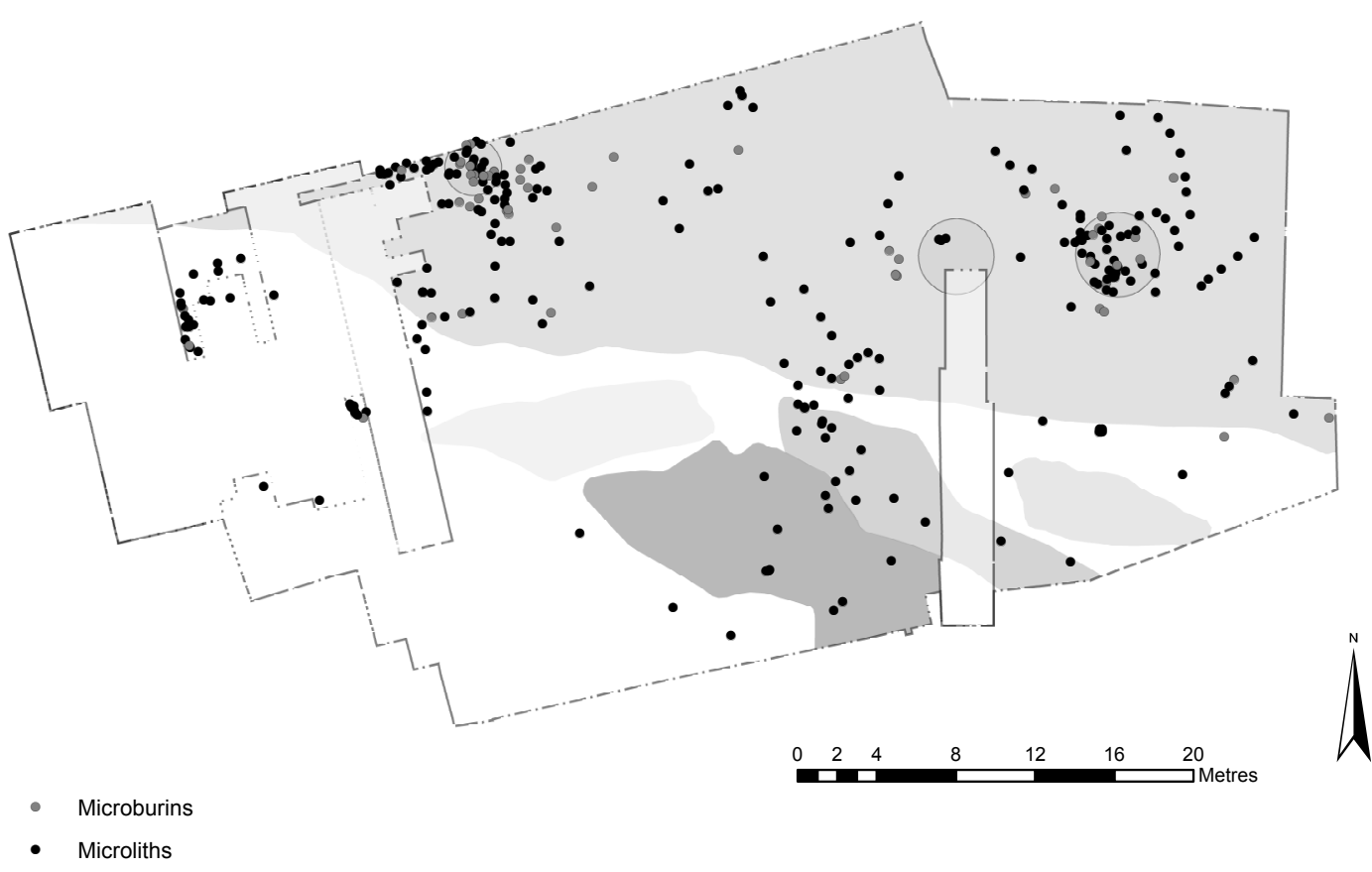

Figure 35.12: Distribution of microliths and microburins across the site (Copyright Star Carr Project, CC BY-NC 4.0).

sequences indicate that axes were reworked and resharpened; however, none retains an entire refit sequence from manufacture through resharpening to discard. This probably indicates axes were mobile tools that underwent a high level of curation and were carried from site to site as personal equipment. With the exception of the preform, roughouts and manufacturing sequences do not seem to be present around Lake Flixton, possibly suggesting roughing out or manufacture at source. However several resharpening sequences are present at Star Carr, indicating a desire to prolong the life of this tool type.

The presence of several refitting sequences reveals the techniques used in axe manufacture and resharpening. Tabular or semi-tabular pieces, or even in cases large flakes, seem to have been preferred, as they were easier to reduce into the desired form. Simple resharpening took place through the removal of a single tranchet flake. More complex resharpening sequences, where reshaping was also required, was brought about through the use of tranchet blows to sharpen the obverse tip of the axe, while the surface created by the tranchet blow was used as a platform for the removal of longitudinal thinning flakes and blades along the reverse face. This was used to adjust the angle, which was then refined by a tranchet blow along the obverse side of the axe tip. This sequence could occur either using the same face for all tranchet blows (Figure 8.39), or alternating the face, so tranchet blows and longitudinal thinning flakes occurred on both faces (Figure 8.41). Additional transverse thinning flakes were also removed from the long margins of the axe. Simple resharpening sequences seem to have occurred with the axe remaining within its haft. More complex sequences, at least on occasion, involved the dehafting of the axe and the sharpening of the end previously enclosed within the haft. The tranchet blow on the longer sequences is always removed from the left. This is likely to be related to predominant right-handedness of the makers of these axes. Axes and sharpening flakes from the axe workshop indicate these tasks were carried out only by right-handed individuals.

Within the Vale of Pickering, axes are rarely found in wetland areas (Figure 35.16), with a single example uncovered during fieldwork by the Vale of Pickering Research Trust on No Name Hill. In contrast they are common in fieldwalked collections from the Vale, such as the Stuart Feather collection (see Table 35.11), which 

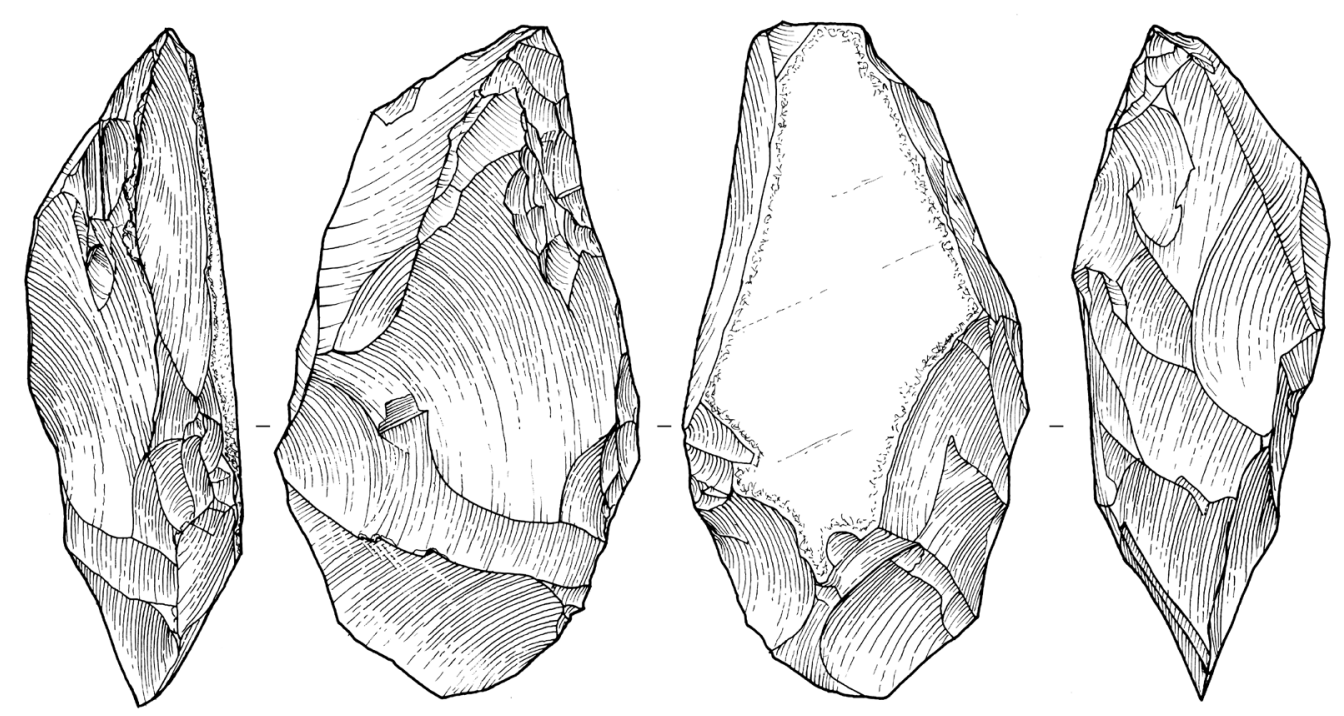

99150
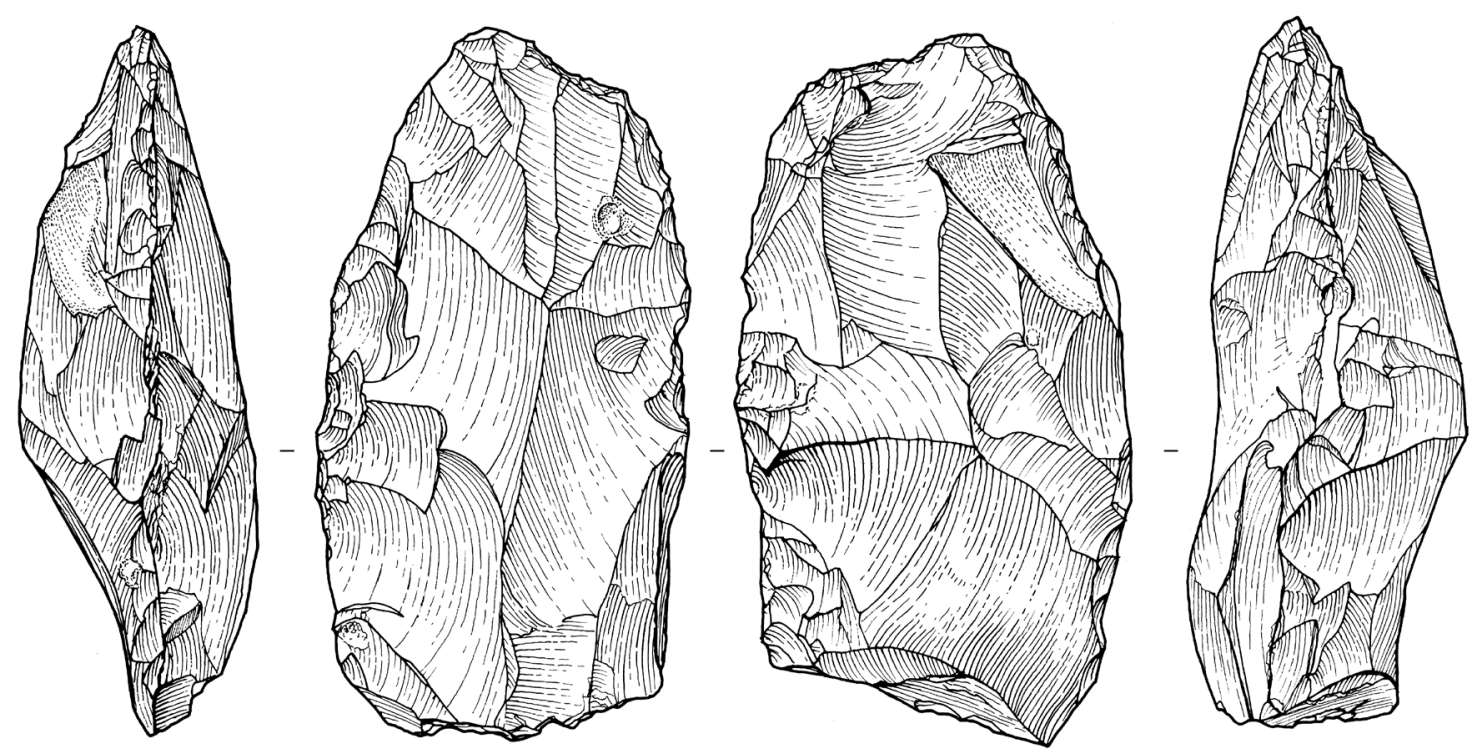

109798

0 $2 \mathrm{~cm}$

Figure 35.13: Axes (Copyright Craig Williams, CC BY-NC 4.0).

preferentially target higher areas, well beyond the former lake shore, that have been truncated by the plough. The same pattern is broadly, but not entirely, true of Star Carr, as axes are not found in the wetland, but are present on the wetland edge as well as the dry ground. They also have a strong association with structures: three were found in the eastern structure, while one was found in the western structure, with another two examples in the immediate surrounding area. However, the largest cluster of axes on site comes from the wetland edge 'axe workshop'; here six axes, and a large quantity of manufacturing and resharpening debris was recovered from peat above the central platform. These activities took place within a $5 \times 4 \mathrm{~m}$ area with three axes found 

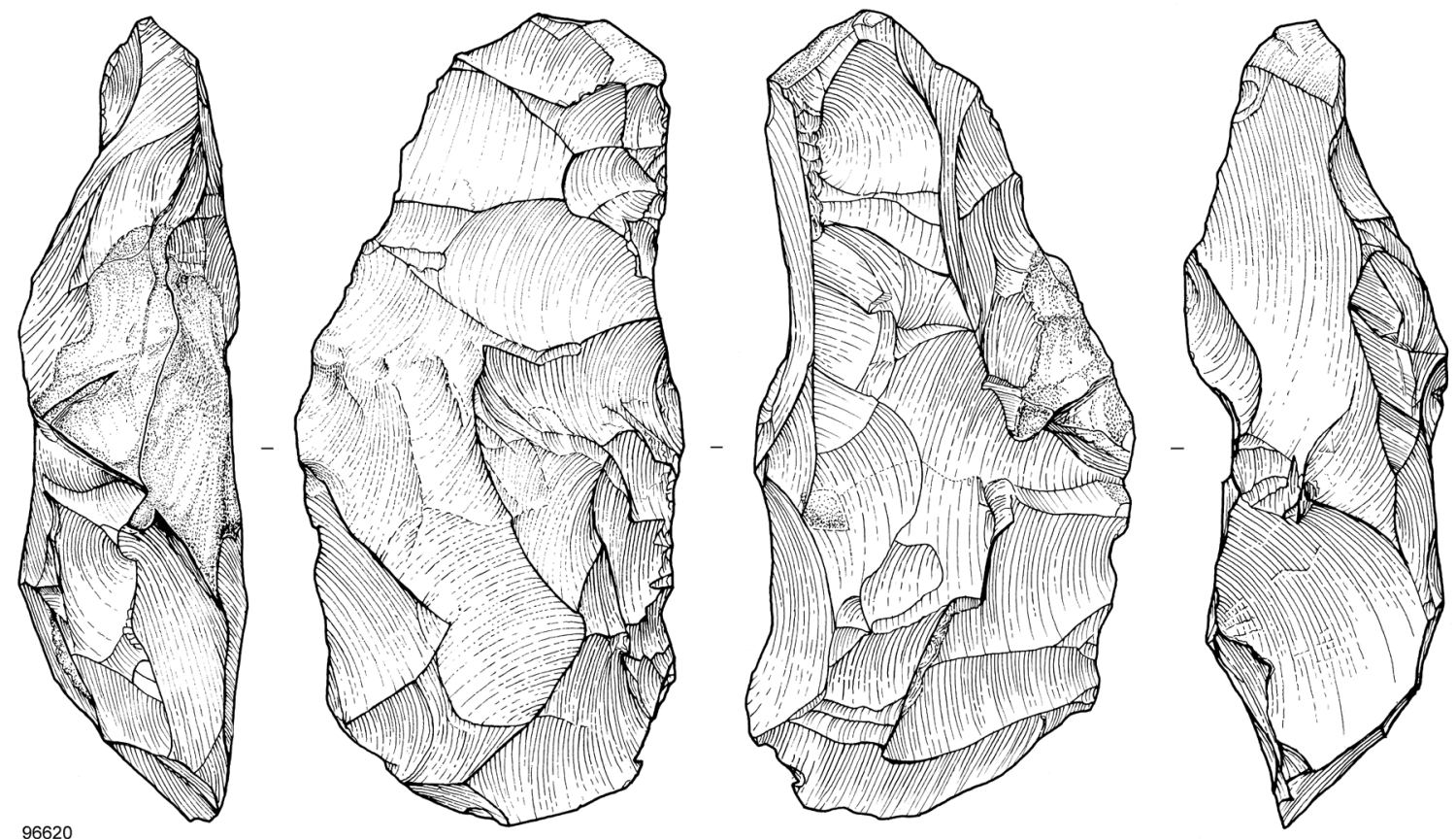

0 $2 \mathrm{~cm}$

Figure 35.14: Triangular sectioned axe (Copyright Craig Williams, CC BY-NC 4.0).

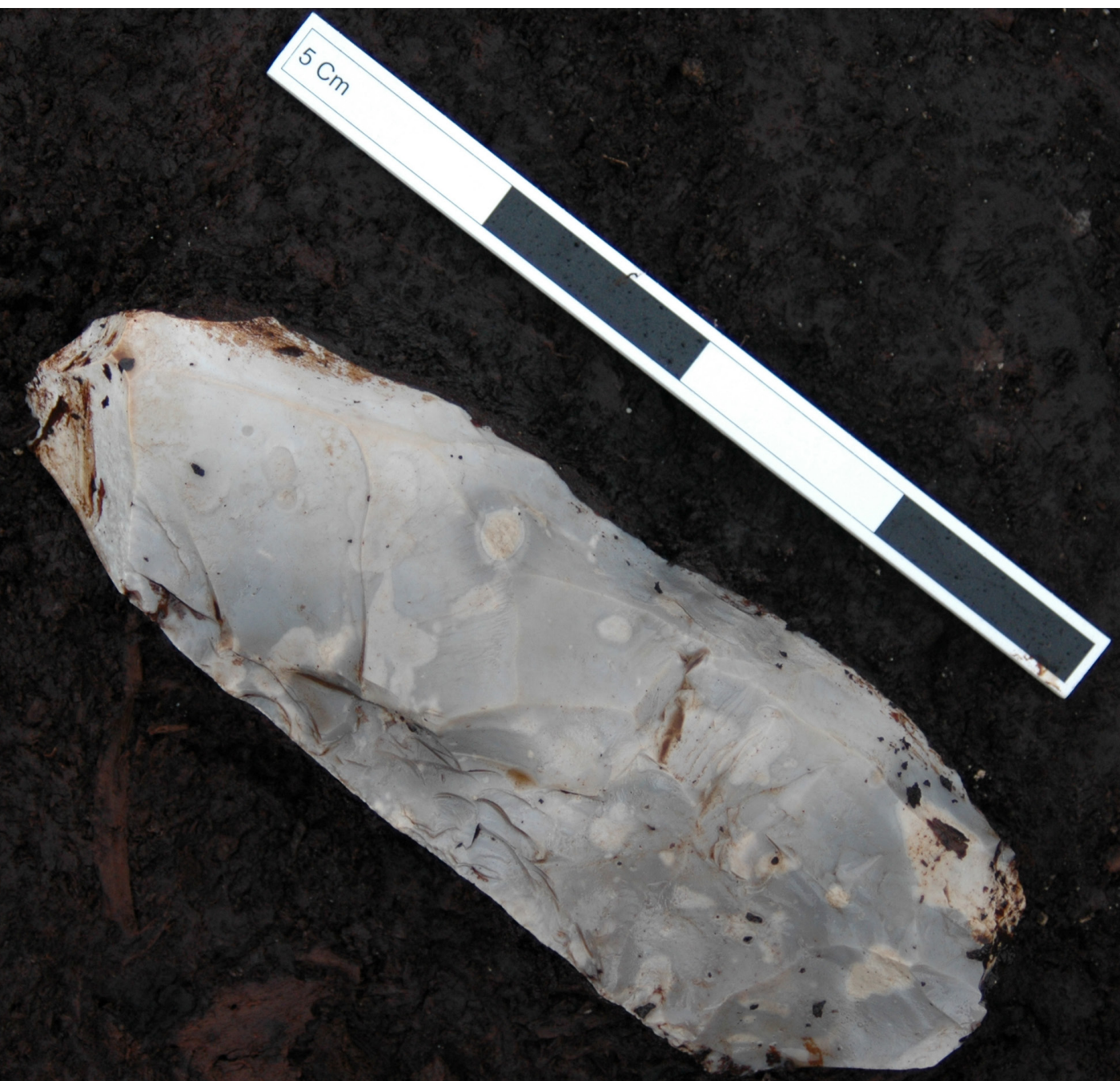




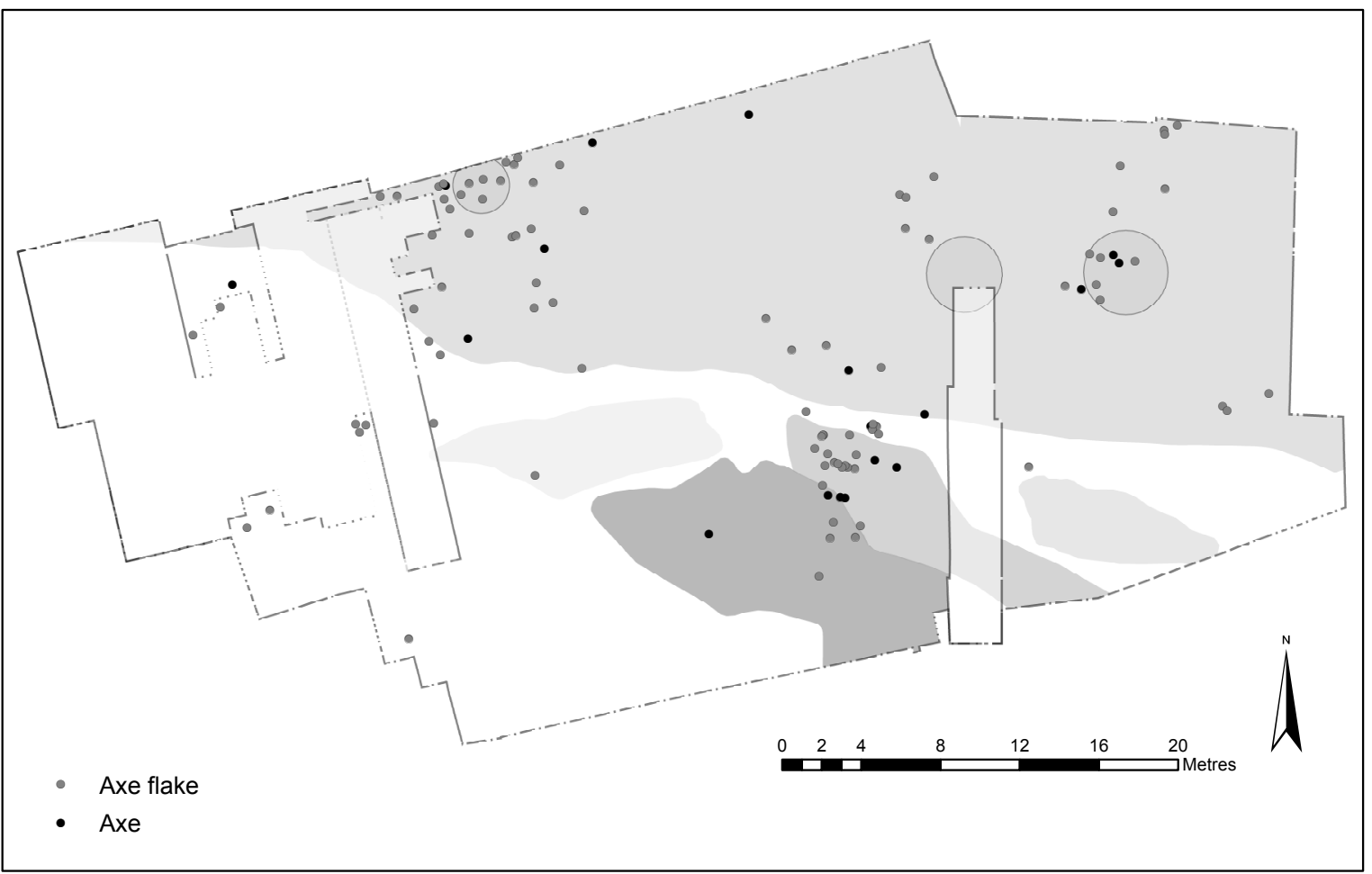

Figure 35.16: Distribution of axes and axe flakes (Copyright Star Carr Project, CC BY-NC 4.0).

\begin{tabular}{|l|r|}
\hline Site & No. of axes \\
\hline Star Carr (mainly north of the Hertford Cut) & 6 \\
\hline Ling Lane & 4 \\
\hline Killerby Carr & 1 \\
\hline No Name Hill & 2 \\
\hline
\end{tabular}

Table 35.11: Axes recovered from the Vale of Pickering through fieldwalking by Stuart Feather between 1960 and 1969.

within an area of less than a metre. One of the axes was found immediately below burnt area [318], indicating a date in the 89th century for the axe workshop (see Chapter 17).

In the area of the axe workshop, two axes (one of Wolds flint, one of till flint) were possibly manufactured from preforms but probably represent finished objects that instead underwent extensive reworking and reshaping in this area. Neither of these two axes was found on site. A third axe (Figure 8.39) was extensively reworked, lightly used and then discarded. A further two were reshaped, resharpened and discarded. These three examples were all recovered from the area, as were two further extremely small axes which do not have any refitting debris. At least two further axes seem to have been present at one time in this area as tranchet flakes from additional Wolds raw material units were recovered.

Figure 35.15 (page 512): Large flint axe preform <96773> in situ (Copyright Star Carr Project, CC BY-NC 4.0). 
Eight axes and three refitting tranchet flakes were analysed for wear traces (Table 35.12). Two of the tranchet flakes displayed no wear, the third, $\langle 98825\rangle$, (from refit group 89, Figure 8.41) had transverse wood traces which could suggest it had been used for scraping but were more likely the result of past chopping activity when attached to the axe; the flake was then removed through rejuvenation. An axe, <92077>, located in the eastern structure was also utilised to chop wood and displays possible binding traces but overall exhibits very little hafting damage. Its presence in the house suggests an episode of repair. Of the four very small axes analysed, two displayed wood-working traces commensurate with being used in a chopping motion. One of these, $<99469>$, was used for a relatively short duration of time; the other, <94367>, (refit group 88, Figure 8.38) was more intensively used. Two axes $(<99447>,<99101>$ ) appeared not to have been utilised (Figure 8.38). These also displayed a distinctive post-depositional surface modification (PDSM) across most of their surfaces, which was at odds with the freshness of the flint and contrasted with the general lack of such PDSM on other flint tools from the wetland area, including the other two very small axes which displayed wear traces. One possibility is that these axes had a different life history, and through transportation, perhaps wrapped or in in a bag, their surfaces have become affected, as recognised microscopically for a number of axes dating to the Neolithic (Wentink 2006). In such a scenario they must have been wrapped or bagged separately, as there is no microchipping or any other evidence to indicate contact with another hard material. Despite this surface alteration, it is unlikely that use traces, if present, have been overlooked as there is very little microchipping damage to the working edge. Given the lack of damage and evidence for use, either these axes were only used for a very short duration of time, or working traces were removed during resharpening (although no hafting wear was identified either), or they were simply not utilised at all. All things combined (location, possible transportation wear, lack of use-related traces), these small axes are certainly intriguing.

Dumont's analysis of 26 core resharpening flakes revealed just one piece with traces, which were, as expected, derived from woodworking.

Awls

Sixty-nine awls were recovered from the excavations (Figure 35.17). The majority of these are bilaterally abruptly retouched convergent truncations (mèches de foret or drill-bits). While many of these are fully retouched along

\begin{tabular}{|l|l|r|}
\hline Primary contact material & Primary action & No. \\
\hline Not used & n/a & 7 \\
\hline Wood & Chopping (3) Wedging or scraping (1) & 4 \\
\hline Total & & 11 \\
\hline
\end{tabular}

Table 35.12: Microwear analysis results for axes and tranchet flakes.
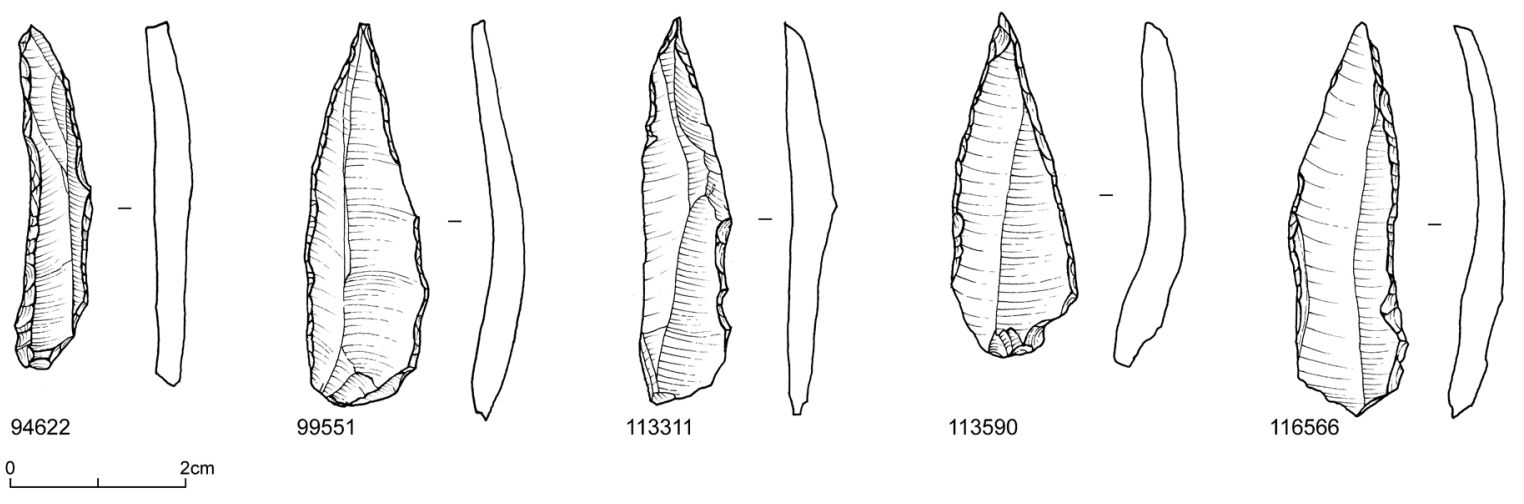

Figure 35.17: Selection of awls (Copyright Craig Williams, CC BY-NC 4.0). 
both laterals, some are only partially retouched, and others are fully retouched on one side only. Complete examples range in length from $81 \mathrm{~mm}$ to $30 \mathrm{~mm}$, in width from 8 to $21 \mathrm{~mm}$ and in thickness from 3 to $9 \mathrm{~mm}$. Average dimensions are $44.1 \times 12.8 \times 4.6 \mathrm{~mm}$. Only 27 examples are complete, many missing the tip, a breakage pattern that was commonly replicated during experiments using awls to manufacture shale and amber beads (Chapter 33).

Nineteen awls have been studied for microwear (Table 35.13). Of these, six displayed soft mineral polish (Fig 35.18), four bone, three siliceous plant (Fig 35.18), two hide, one was used on an indeterminate hard material (antler and/or bone?), one was indeterminate and three had no evidence of use. Interestingly, the awls used to work mineral, hide and bone were typically used in a piercing or drilling motion, except for a large double-ended awl which had been used in a longitudinal motion to saw as well as drill. The siliceous plant-working tools had polish that was both transverse and parallel to the edge, indicating cutting and scraping motions. Apart from two awls used to work a soft mineral which had possible signs of hafting, no other awl displayed hafting wear. It is thus likely that these tools were mostly handheld.

As discussed in Chapter 33, our experimental research, which aimed to replicate the soft mineral polish seen on several of the awls, demonstrated that a comparable polish developed when drilling shale. This, in conjunction with their spatial distribution (focused on the western area of the site where beads were recovered in these and Clark's excavations, (Figure 35.19) strongly suggests that the soft mineral polish on many of the awls is a

\begin{tabular}{|l|l|l|r|}
\hline Contact Primary contact material & Secondary contact material & Action & No. \\
\hline Mineral (soft) & & Drilling & 6 \\
\hline Hide & Mineral & Piercing & 2 \\
\hline Plant (siliceous) & & Cutting/Scraping & 3 \\
\hline Bone & & Drilling & 4 \\
\hline Indet hard material & & Drilling/sawing & 1 \\
\hline Indet. use & & Indet. & 1 \\
\hline Not used & & n/a & 3 \\
\hline Total & & & 20 \\
\hline
\end{tabular}

Table 35.13: Microwear analysis results for awls.
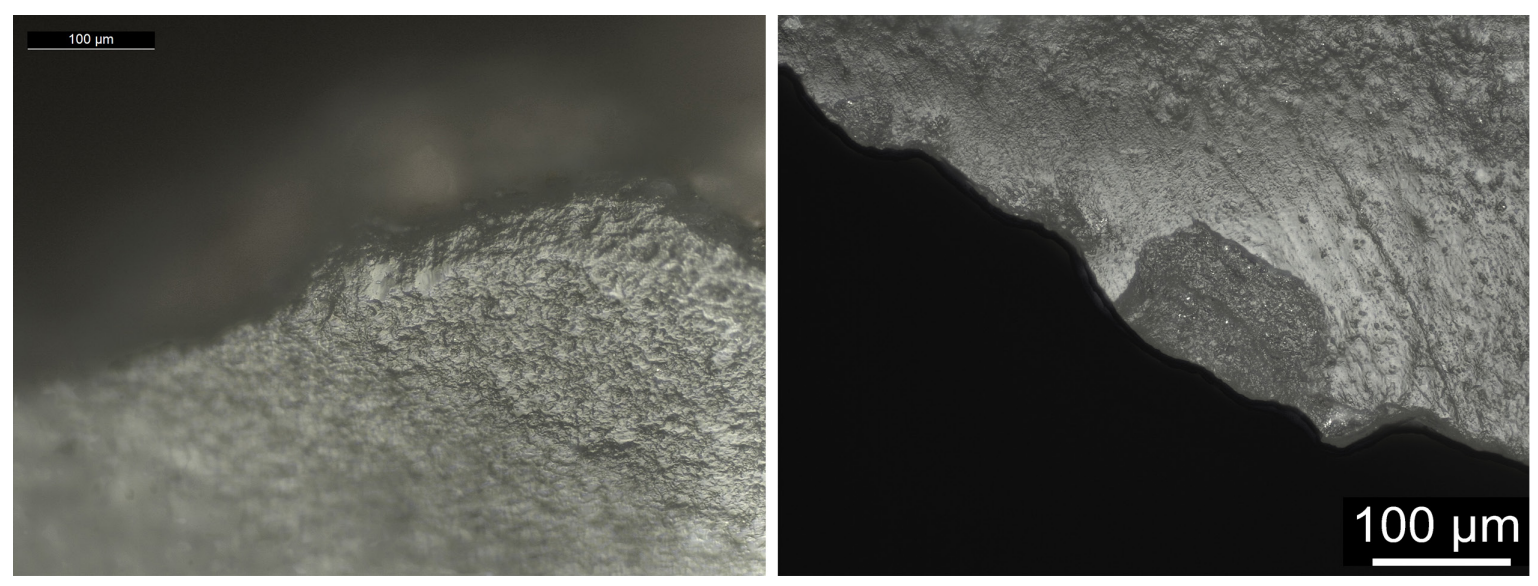

Figure 35.18: (left) awl <93991> exhibiting evidence for soft mineral polish ( $\times 20$ magnification); (right) awl $<93521>$ exhibiting evidence for siliceous plant polish with oblique directionality (Copyright Aimée Little, CC BY-NC 4.0). 


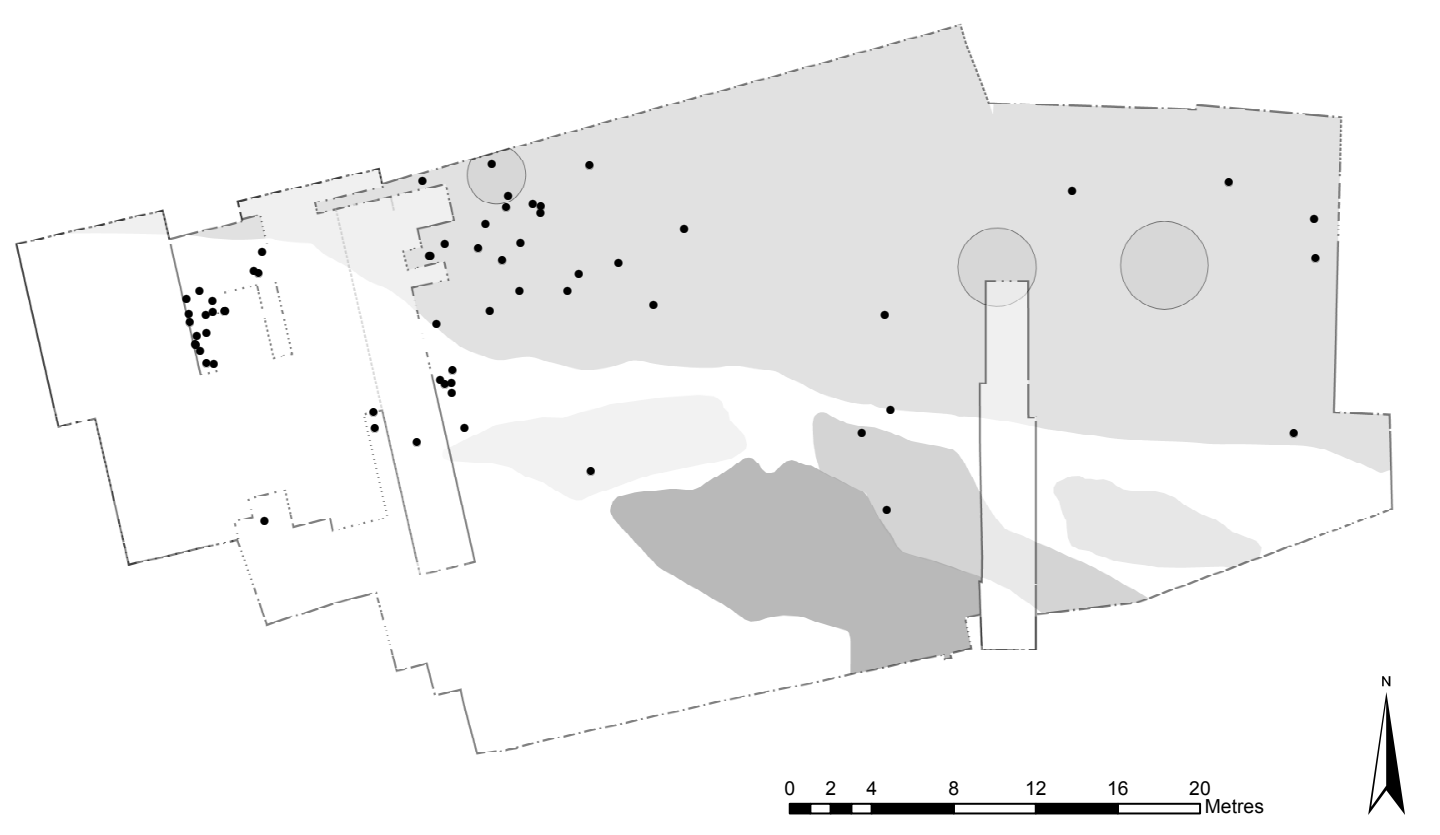

Figure 35.19: Distribution of awls on site (Copyright Star Carr Project, CC BY-NC 4.0).

result of their employment to drill shale beads. Microwear evidence for awls being used to pierce hide, with a mineral additive (ochre?), the drilling of bone, and the working of siliceous plants, further indicates that awls were multifunctional craft tools.

Dumont's analysis of 28 awls, of which 15 had traces and 11 of which were identifiable, revealed a much greater proportion of bone-working $(n=8)$, as well as wood $(n=2)$; the latter was not present on the awls studied as part of this research. He also identified one hide-working tool. It is somewhat surprising that no mineral polish was identified, given the number of mineral-working awls identified in our study. Again, various reasons can be proposed, including a genuine absence of mineral-working awls in Dumont's sample (and therefore from Clark's area). Alternatively perhaps, given the smooth/flat and often restricted distribution of mineral polish (albeit much duller and textured in appearance than bone polish), Dumont was not making a distinction between bone and mineral. In attempting to justify why so many awls had bone-working traces when there is very little evidence for bone objects with perforations at Star Carr, Dumont $(1989,233)$ suggests the awls could have been used to produce the perforations in the frontlets. Though he concedes that the frontlet holes are far larger than those which would be produced using the awls (see Little et al. 2016 for further discussion on frontlet perforation techniques), he suggests that the awls were instead used to enlarge the parietals on the front of the crania. Interestingly, one awl $<113871>$ with 'bone' drilling traces was found in the bead area, amongst awls used to drill soft mineral, probably shale. Although yet to be replicated experimentally, it is possible that this tool was used to drill red deer teeth pendants. The size of teeth pendant perforation fits well with the morphological size of the awls and may account for why so many bone awls were identified by Dumont when so little other evidence for bone drilling exists amongst the faunal assemblage at Star Carr.

With only nine exceptions, awls were found clustered in the western area of the site. They are associated mainly with the bead area (18 examples) and the area south and southwest of the western dryland structure (the midden) (29 examples). There are some indications that the awls belong to the middle and later phases of the use of the site. There are three in the axe workshop which dates to between c. 8900-8800 cal BC (based on 
the dates of the underlying central platform, and the overlying burnt area [318]), two in Clark's area, also dating to c. $8800 \mathrm{cal} \mathrm{BC}$, and several in the midden which probably also dates to this period (See Chapters 9 and 17). The intense activity relating to bead manufacture involving the use of 17 examples, probably belongs to the 88th century cal BC (see Chapter 9, and Figure 17.6). Finally the cluster of five awls in the fen flint scatter, immediately to the east of Clark's trench, is very high in the sequence and relates to activity that took place in or after $8670-8475$ cal BC (95\% probability; TPQ fen flint; Figure 17.9), probably in or after 8605-8515 cal BC (68\% probability).

\section{Burins}

A total of 232 burins were recovered from the excavations (Figure 35.20, 35.21, Table 35.14). The majority of these are angle burins $(n=135)$, variously on truncations, breaks or natural surfaces (such as plunging terminations). Dihedral burins are present but make up a relatively small proportion of the assemblage. This latter form is the most common type on Long Blade sites in the Vale of Pickering, but there does not seem to be a chronological component to the use of dihedral burins at Star Carr. Burins range in length from 21 to $82 \mathrm{~mm}$, in width from 7 to $58 \mathrm{~mm}$ and in thickness from 2 to $25 \mathrm{~mm}$, with average dimensions of $45.3 \times 25.4 \times 10.2 \mathrm{~mm}$. In comparison with awls and scrapers, relatively thick supports have been selected.

Burins appear to have been tools that underwent some movement and curation, though not to the same extent as axes. They were almost always moved from their place of manufacture, not always very far (an example from central structure surrounds was found $5 \mathrm{~m}$ from the knapping scatter in which it was made), though others were moved around more widely. Burins were manufactured in the eastern structure (as indicated by large numbers of primary burin spalls), but a lack of refits indicates most of these were moved for use elsewhere. A burin made in scatter 4 was moved $6.3 \mathrm{~m}$ north and used in scatter 1 . However, burins are often found close to their final resharpening spalls, indicating they were often abandoned in the areas in which they were used (Figure 35.22).

Despite the suggestion of Andresen et al. (1981) that burins, in particular the side edges of the burin facet, were probably being used as scrapers for hard contact materials such as wood, bone and antler, burin use at Star Carr involved a broad range of contact materials and actions (Table 35.15). Whilst wood was the most commonly worked material $(n=5)$ (Figure 35.23), followed by bone/and or antler $(n=2)$ and an indeterminate hard material $(n=2)$, they were also employed to work mineral $(n=2)$, fish $(n=1)$, plant $(n=1)$ and another indeterminate soft material. Scraping of wood was most common, though burins were also used to groove and whittle wood. In fact, across the spectrum of contact materials burins were used on, we see much greater diversity in activities than suggested by Andresen and colleagues (1981). Not just the burin facet was employed; other edges were too. In essence, the multi-faceted and often robust morphology of these tools lent themselves to a range of functions.

\begin{tabular}{|l|r|}
\hline Burin type & No. \\
\hline Angle burin on break & 48 \\
\hline Angle burin on natural surface & 27 \\
\hline Angle burin on truncation & 60 \\
\hline Dihedral burin & 24 \\
\hline Double angle burin & 33 \\
\hline Double burin-angle and dihedral & 8 \\
\hline Triple burin & 6 \\
\hline Quadruple burin & 4 \\
\hline Misc/fragment & 22 \\
\hline
\end{tabular}

Table 35.14: Burin types. 

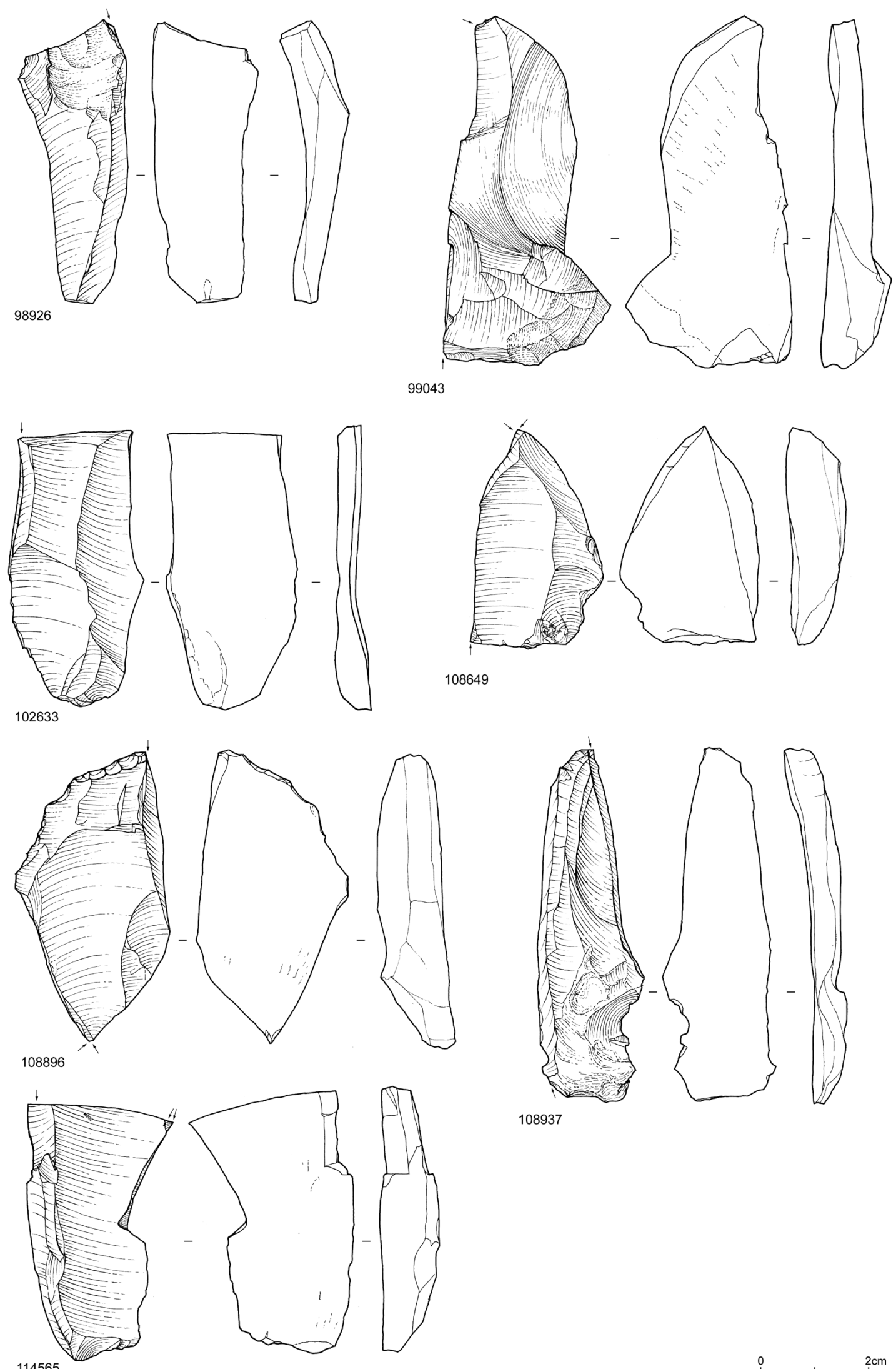

114565

Figure 35.20: Burins (Copyright Craig Williams, CC BY-NC 4.0). 

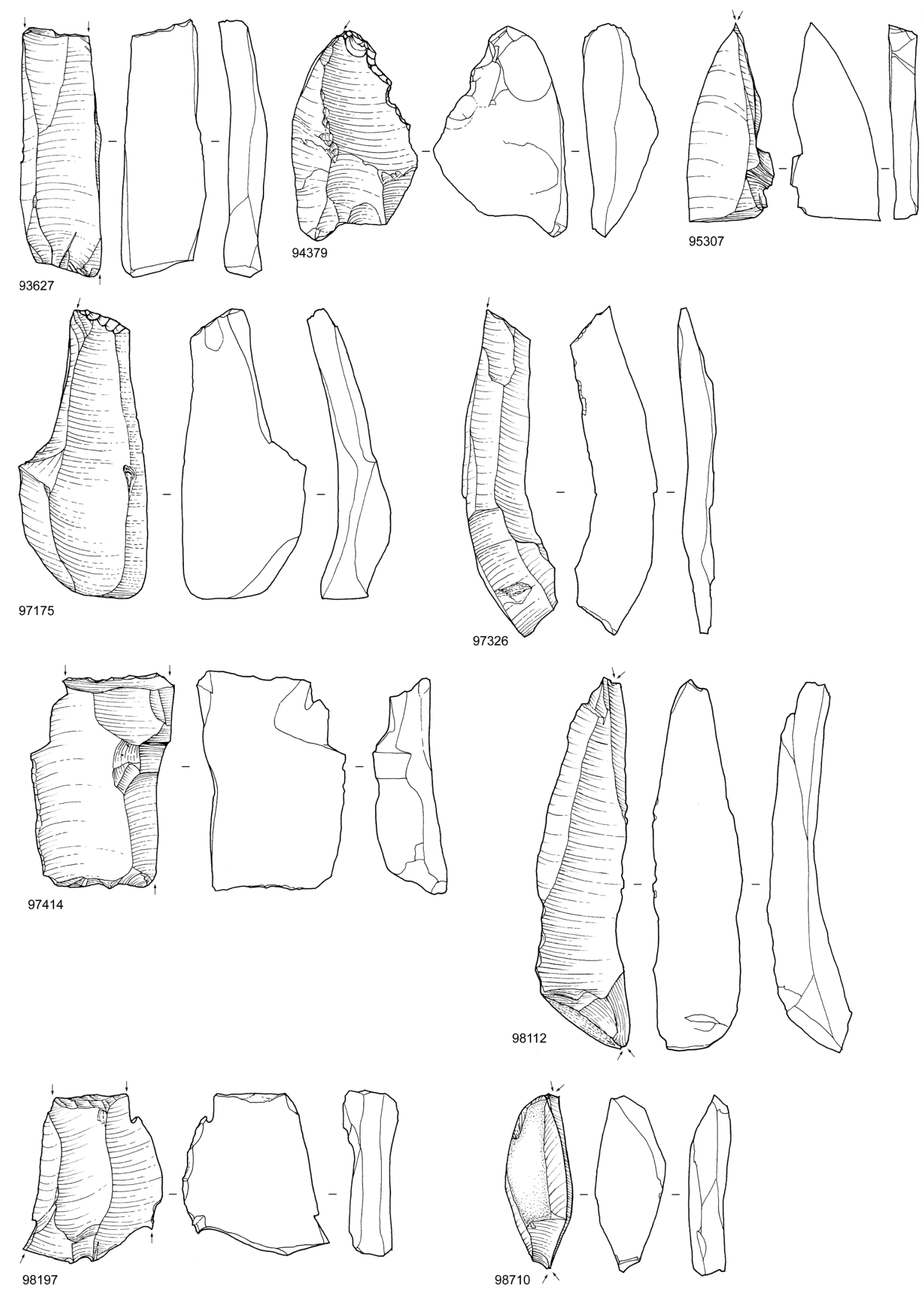

0 $2 \mathrm{~cm}$

Figure 35.21: Burins (Copyright Craig Williams, CC BY-NC 4.0). 

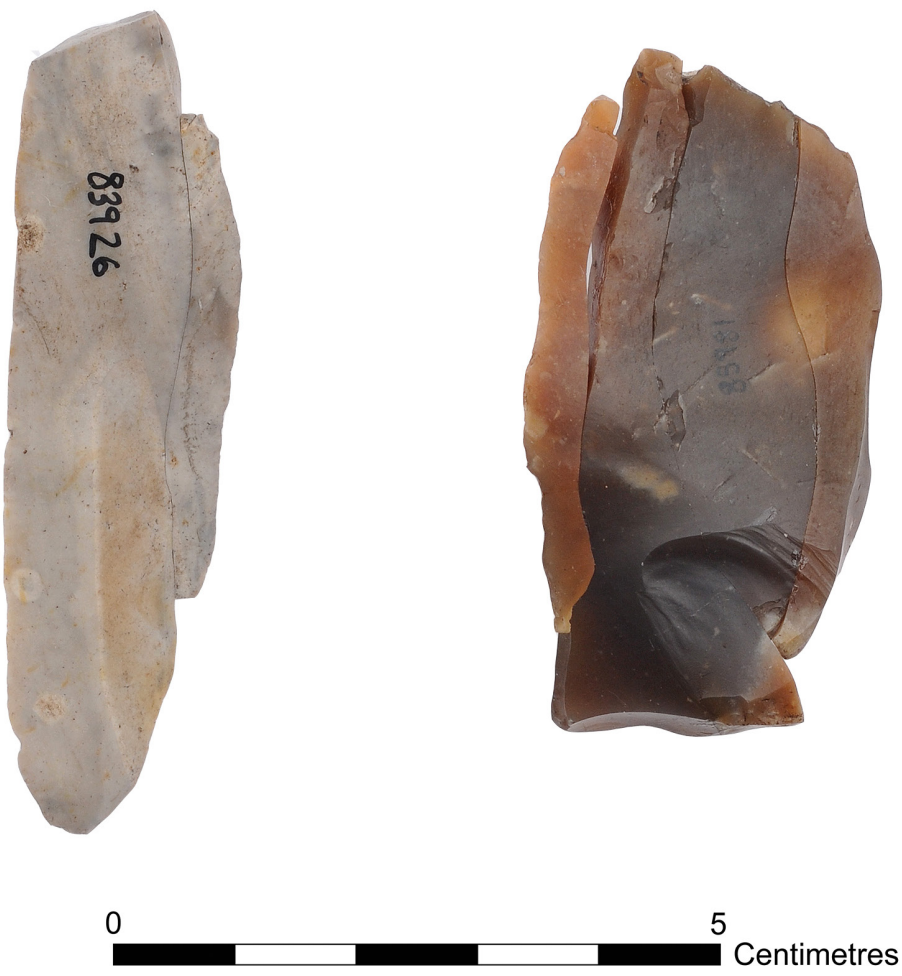

Figure 35.22: Refitting burins and burin spalls (Photograph taken by Paul Shields. Copyright University of York, CC BY-NC 4.0).

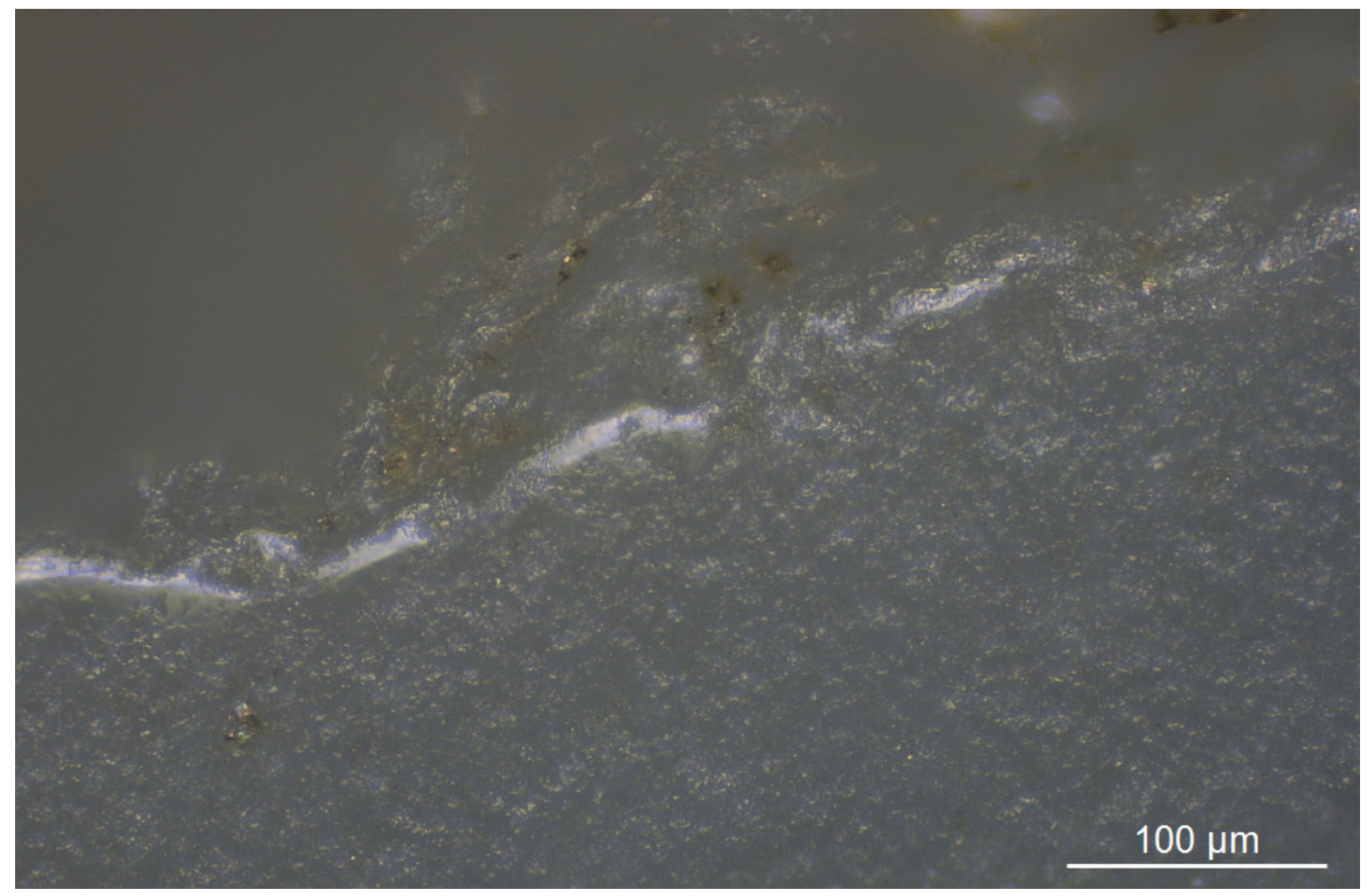

Figure 35.23: Transverse wood polish on burin <117501> (Copyright Aimée Little, CC BY-NC 4.0). 


\begin{tabular}{|c|c|c|}
\hline Contact material & Action & No. \\
\hline Wood & Scraping (3; one of which was burin spall), Scraping/Grooving (1), Whittling/Scraping (1) & 5 \\
\hline Hard material indet. & Cutting (1), Boring/Scraping (1) & 2 \\
\hline Bone and/or antler & Grooving (1), Grooving/Scraping (1) & 2 \\
\hline Mineral & Cutting (1), Scraping (1) & 2 \\
\hline Plant (medium hardness) & Cutting & 1 \\
\hline Soft material indet & Scraping & 1 \\
\hline Fish & Cutting/scraping & 1 \\
\hline Indet. & Indet. & 1 \\
\hline Un-analysable & $\mathrm{n} / \mathrm{a}$ & 1 \\
\hline Not used & $\mathrm{n} / \mathrm{a}$ & 4 \\
\hline Total & & 20 \\
\hline
\end{tabular}

Table 35.15: Microwear analysis results for burins.

Burins are found across the site (Figure 35.24). On the dryland both burins and burin spalls have been recovered indicating both manufacture and use. These have strong associations with the structures and their surrounding areas, in particular the various scatters to the north of the eastern structure. The eastern structure was an area where burins were manufactured for use elsewhere, as indicated by the large number of primary spalls (Figure 35.25); the assemblage from the western structure is more balanced between primary and secondary spalls. In the wetland and wetland edge area, burin spalls are rarer (though they do occur in the area north of cutting III (bead area), Clark's area and the axe workshop), and when present are mainly resharpening rather than manufacturing spalls. The two examples found in open water, from the area south of cutting III and the detrital wood scatter, are both large plunging burin spalls that may have both been used as tools. Burins themselves are found in reasonably large numbers indicating use and/or deposition in these areas.

\section{Scrapers}

The assemblage contains 336 scrapers (Figure 35.26), making these (by a small margin) the most common tool recovered from the site. Scrapers range in length from 18 to $74 \mathrm{~mm}$, in width from 6 to $44 \mathrm{~mm}$ and in thickness from 3 to $25 \mathrm{~mm}$. Average dimensions are $34.6 \times 23.7 \times 8 \mathrm{~mm}$. Almost all scrapers are endscrapers. A small sharp spur is present on some of the scrapers (Figure 35.26: $<95428>$ and $<95980>$ ), a feature also seen on examples from Seamer C. Short endscrapers (that is where the length is less than twice the width) are best represented (Table 35.16). Though some long endscrapers are present, it is likely that the length:width ratio represented by the short scraper was more useful for preventing breakage. Examination of scraper dimensions (Figure 35.27) indicates that while some of the longest scrapers were wider and thicker, in general there does not seem to be a relationship between length, width and, in particular, thickness. This might mean that blanks of broadly similar width and thickness were selected irrespective of length, or that some of the variation in length is due to resharpening practices, with scrapers becoming shorter as they were repaired.

In general scrapers often appear to have been expedient tools for immediate use. There has been a better level of success for refitting scrapers than burins and in general refitting demonstrates scrapers tended not to leave their immediate scatter of manufacture, a pattern found on other sites in the Vale of Pickering, such as Seamer C. Refit distances for scrapers range from 0.5 to $3.5 \mathrm{~m}$, with an average of $2.16 \mathrm{~m}$ distance from the previous removal in the refit sequence. In contrast, burins range from 1.59 to $6.30 \mathrm{~m}$ with an average distance of $4.13 \mathrm{~m}$. 


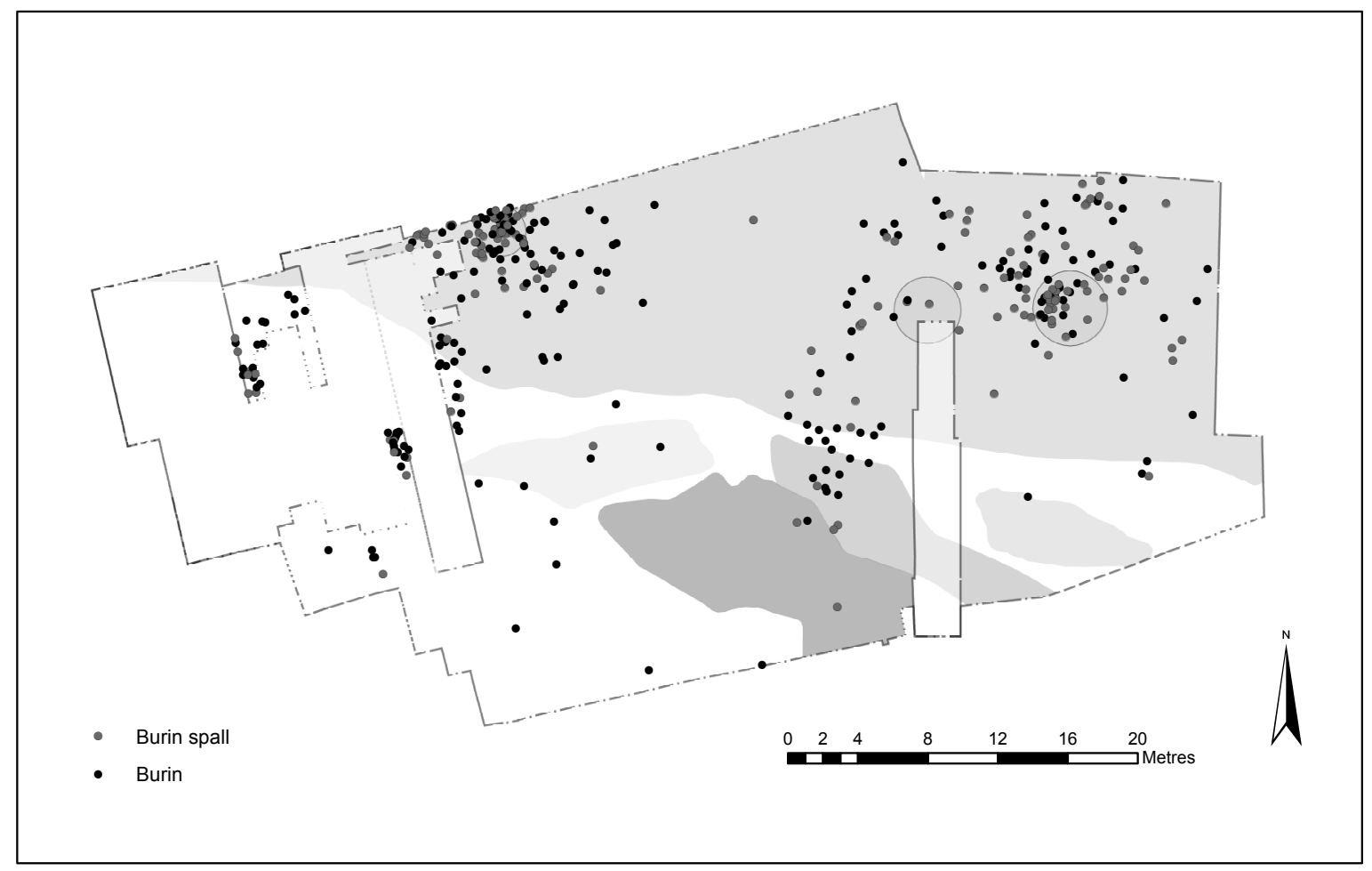

Figure 35.24: Distributions of burins across site (Copyright Star Carr Project, CC BY-NC 4.0).

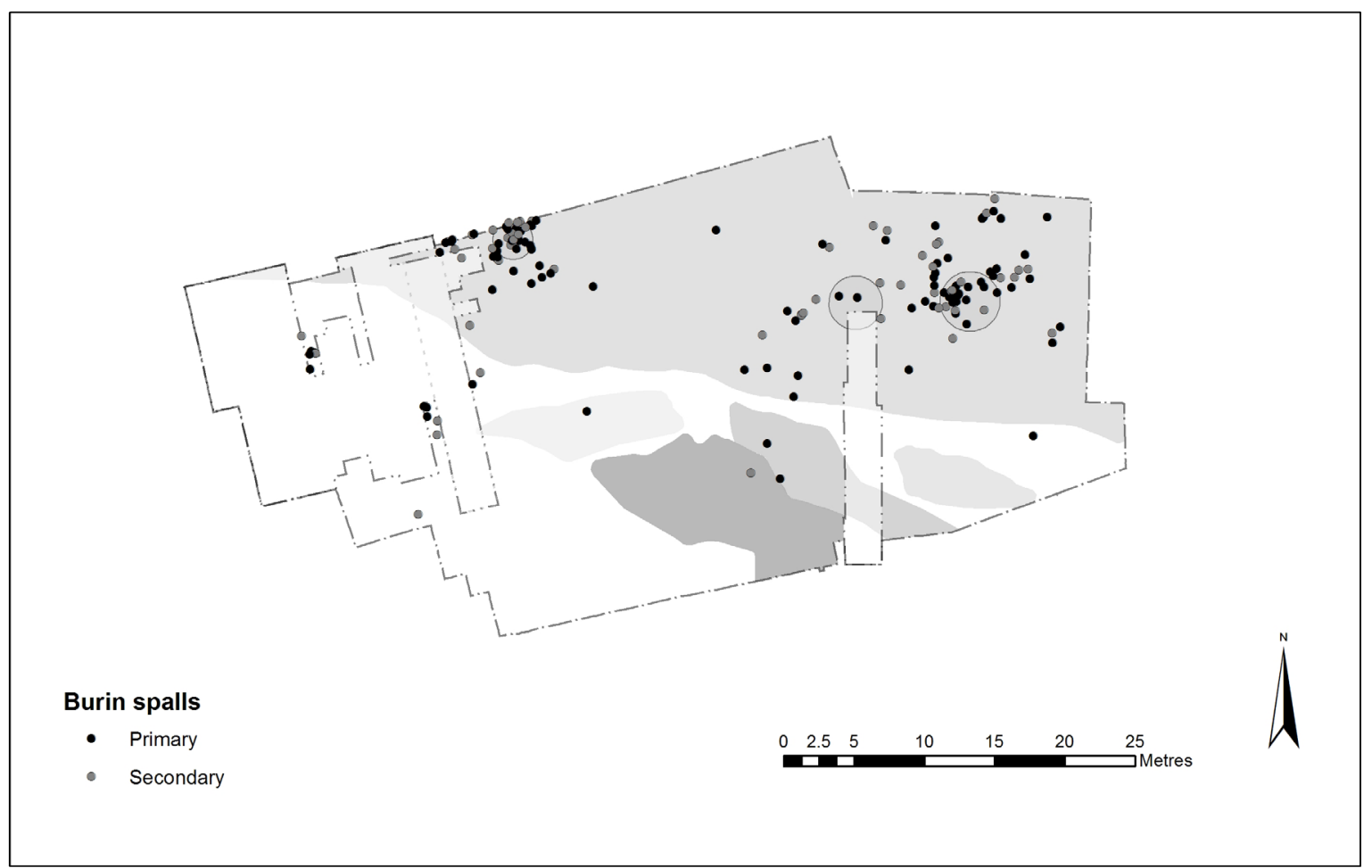

Figure 35.25: Distribution of primary (manufacturing) and secondary (resharpening) burin spalls (Copyright Star Carr Project, CC BY-NC 4.0). 


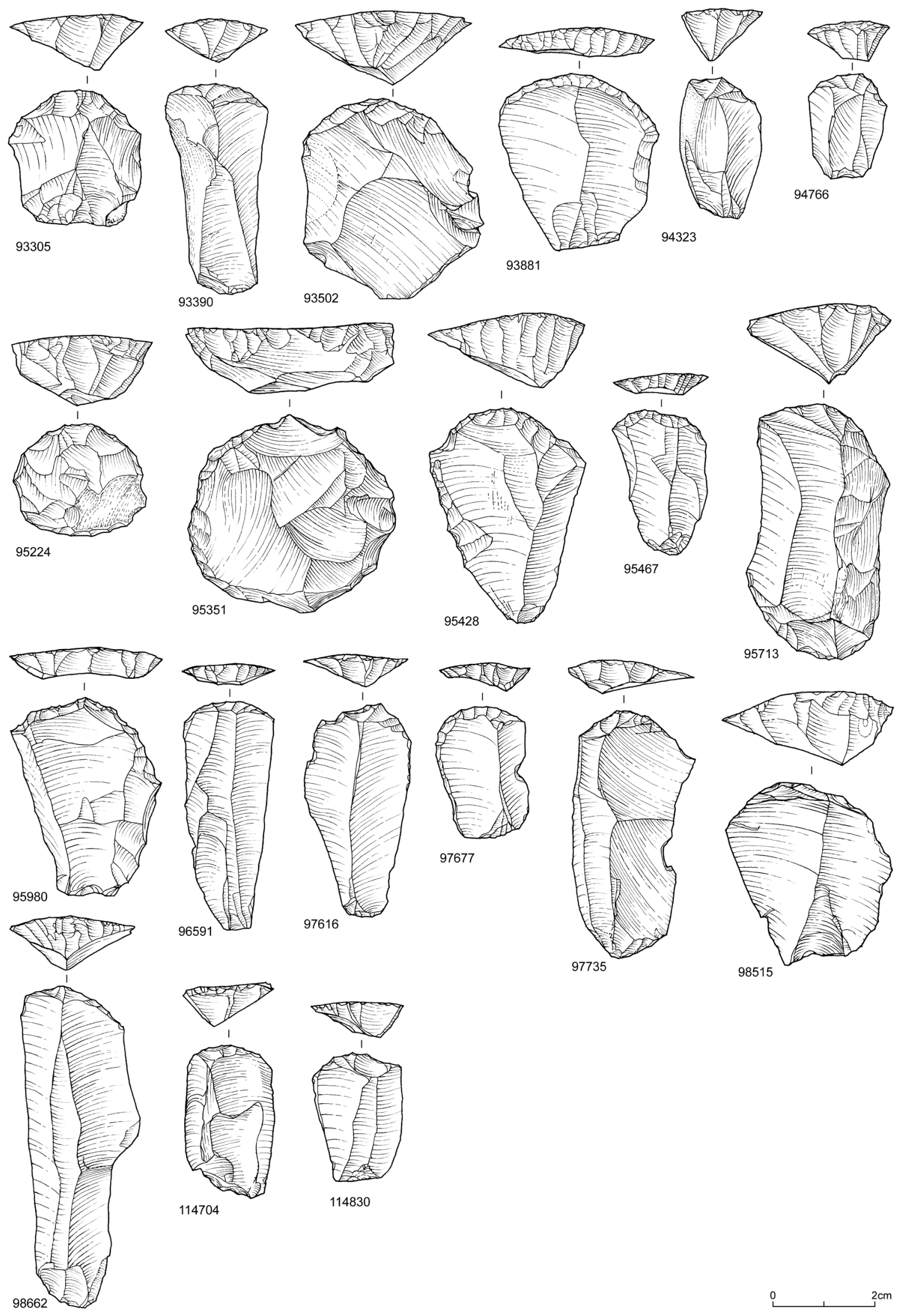

Figure 35.26: Scrapers (Copyright Craig Williams, CC BY-NC 4.0). 


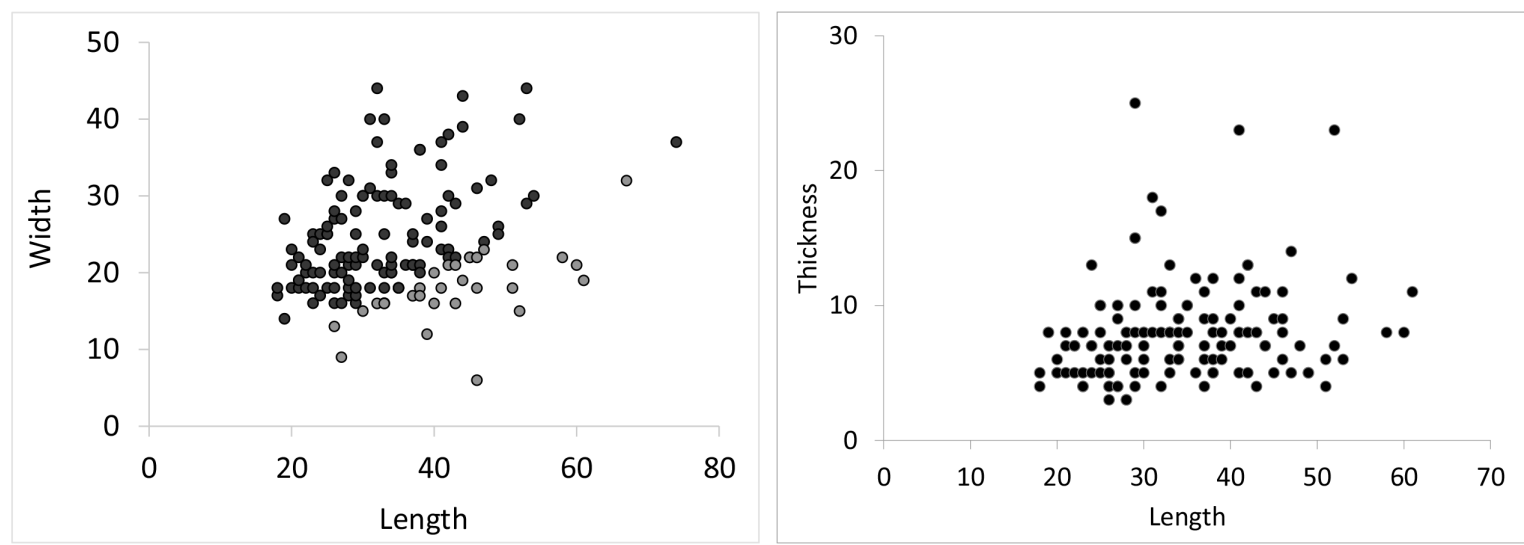

Figure 35.27: (left) length and width of long (grey) and short (black) scrapers; (right) length and thickness of scrapers. All measurements in mm (Copyright Star Carr Project, CC BY-NC 4.0).

\begin{tabular}{|l|r|}
\hline Scraper type & No. \\
\hline Long & 52 \\
\hline Short & 138 \\
\hline Round & 6 \\
\hline Double & 27 \\
\hline Irregular/misc. & 12 \\
\hline Fragment & 98 \\
\hline
\end{tabular}

Table 35.16: Scraper types.

In total, six of the 15 scrapers analysed were used for hide-related activity, either on moisturised or dry hide (Table 35.17). One of these also had mineral traces, probably ochre, which is likely to have been used in the hide preparation. Others had a dual use, one being used for both hide and bone work (a combination also observed by Dumont $(1988,37))$ and another scraper had been used on both plant and bone. Three scrapers (two used on hide, one which had indeterminate contact material because of PDSM) were hafted. Hafting was determined by distribution of intense microchipping, which also suggested no or little use of resin as the damage was very intense. Interestingly, nearly a quarter of all scrapers analysed had no signs of use at all, which, given the fact they are the most ubiquitous tool found at Star Carr, suggests one of two things: provisioning may have been taking place, or that re-sharpening events have removed previous wear traces. Three scrapers have indeterminate wear traces, unidentifiable because of PDSM. In all instances where polish was identified, scraping was the primary action.

Dumont analysed considerably more scrapers $(n=51)$, this being the largest category of tool that he examined. However, for his analysis, he grouped truncated blades and flakes together with scrapers, whereas we have treated these tool types separately. Hide traces were the most common, followed by bone, antler, wood, hide and bone, with lesser numbers displaying combinations of two or more of the above materials. His focus on scrapers led to the determination of two morphologies with two functions, bone working scrapers and hide.

Scrapers have broadly similar distributions to burins, found mainly in and surrounding the structures, and in wetland edge contexts (Figure 35.28). However, some differences are apparent. Scrapers are found mainly to the east and west of the eastern structure, in contrast to burins that are found mainly to the north. Scrapers also seem to have a slightly more extensive wetland distribution than burins, found (albeit still in relatively small 


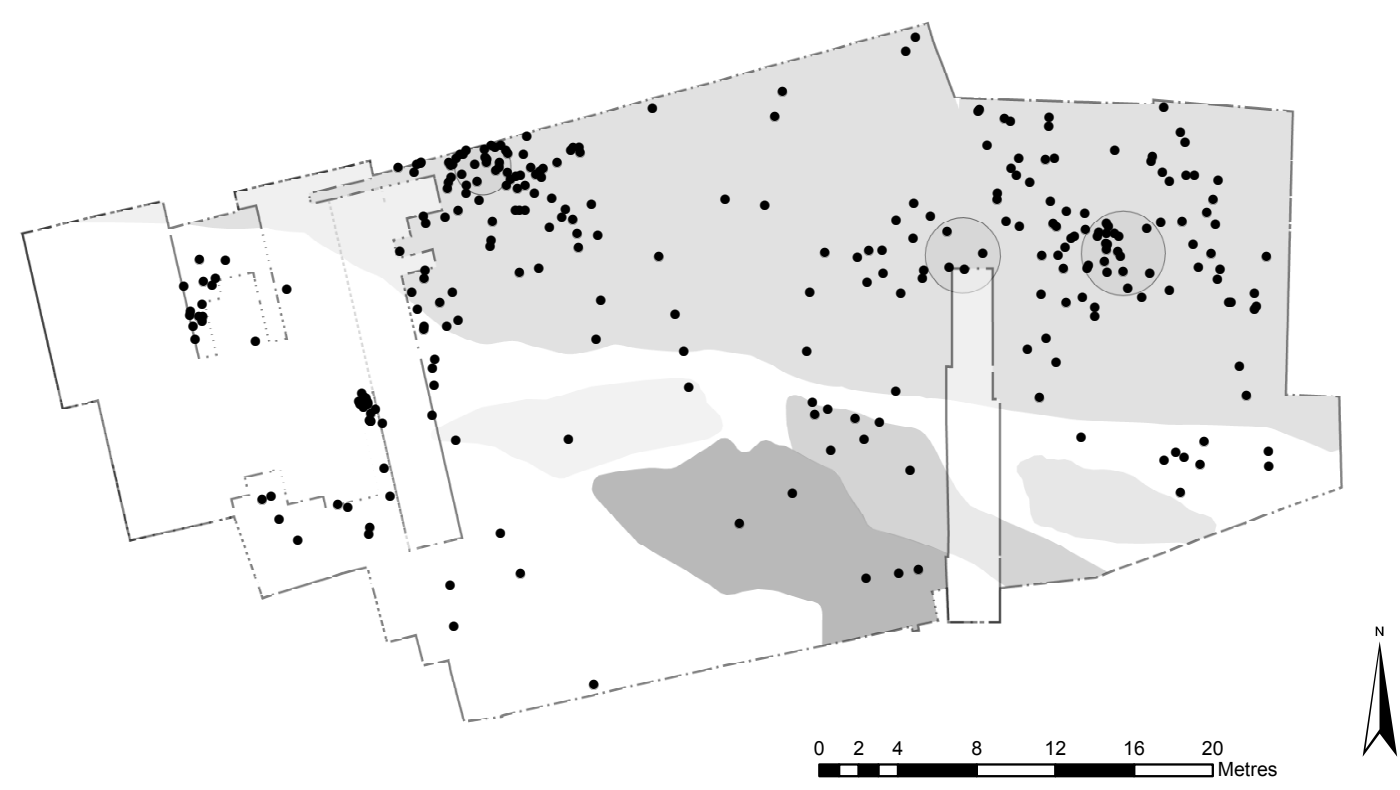

Figure 35.28: Distribution of scrapers (Copyright Star Carr Project, CC BY-NC 4.0).

\begin{tabular}{|l|l|l|l|r|}
\hline Primary contact material & Secondary contact material & Tertiary contact material & Action & No. \\
\hline Hide dry & Hide moist & Mineral & Scraping & 1 \\
\hline Hide dry & & & Scraping & 2 \\
\hline Hide moist & & & Scraping & 1 \\
\hline Hide Indet. & bone $(1 \mathrm{x})$ & & Scraping & 2 \\
\hline Plant & bone & & Scraping & 1 \\
\hline Wood & & & Scraping & 1 \\
\hline Indet. use & & & Indet. & 3 \\
\hline Not used & & & n/a & 4 \\
\hline Total & & & & 15 \\
\hline
\end{tabular}

Table 35.17: Microwear analysis results for scrapers.

numbers) in the southern parts of Clark's area, the marl area and the detrital wood scatter. Areas of scraper manufacture are difficult to isolate, because resharpening spalls are extremely small and usually too small to be captured in the $5 \mathrm{~mm}$ sieves used on site. Only 12 were recovered from excavation and sieving, and a further five recovered from wet sieving of soil samples. Resharpening spalls have been recovered from the western structure, from the northern and southern part of the central structure surrounds, from the fen carr scatter, the northernmost part of Clark's area and from test pits SC8 and SC10 at the top of the Star Carr peninsula. Often these are too small to ascertain whether they derive from an area of straight or curved retouch, so some may relate to the production of truncations for burins. 


\section{Microdenticulates}

Microdenticulates, also known as saws or serrated pieces, are not common at Star Carr or Star Carr sites more broadly. Only 23 examples were recovered, of which 12 were made on blades or bladelets, five on flakes, while the remainder were fragmentary. Use traces are extremely varied: two were used on dry hide, one as a projectile, one for butchery and one for cutting plants. Microdenticulates are more common on Deepcar type-sites, such as Marsh Benham, where 52 were recovered (Jacobi nd). Marsh Benham is a fairly late Deepcar site, and it may be that use of microdenticulates on a broad scale has a temporal component, perhaps related to the presence of particular types of vegetation, as in later Mesolithic contexts these are often plant-working tools. Microdenticulates are found mainly in the western part of the site, in and around the western structure and south of Clark's trenches (Figure 35.29).

\section{Notches and denticulates}

There were 18 denticulates and 13 notches recovered from the site. These are miscellaneous in form, made on flakes, blades, chunks and as denticulate scrapers. In total, 10 pieces classified as notched or denticulate were analysed for wear traces (Table 35.18). Only one of these, $<97569>$, was hafted; this was also the only piece used for butchery. Interestingly, of the two denticulates examined by Dumont, only one piece displayed traces, and these were also connected to butchery. However, most common amongst the current assemblage were woodworking traces $(n=4)$, with tools used to scrape $(n=3)$ or plane $(n=1)$ wood. One of these, $<99174>$, displayed bast polish too, indicating it was a multifunctional woodworking tool. Two pieces were used to scrape bone, one of these, $<98438>$, had very well-developed dry bone-working traces located within a single notch of a multi-notched tool; the notch was used to shave or scrape the bone (Figure 35.30). It is probable that this was a craft tool. Of the three un-utilised pieces, one, the denticulate core, belonged to the X6 cache, a cluster of lithic

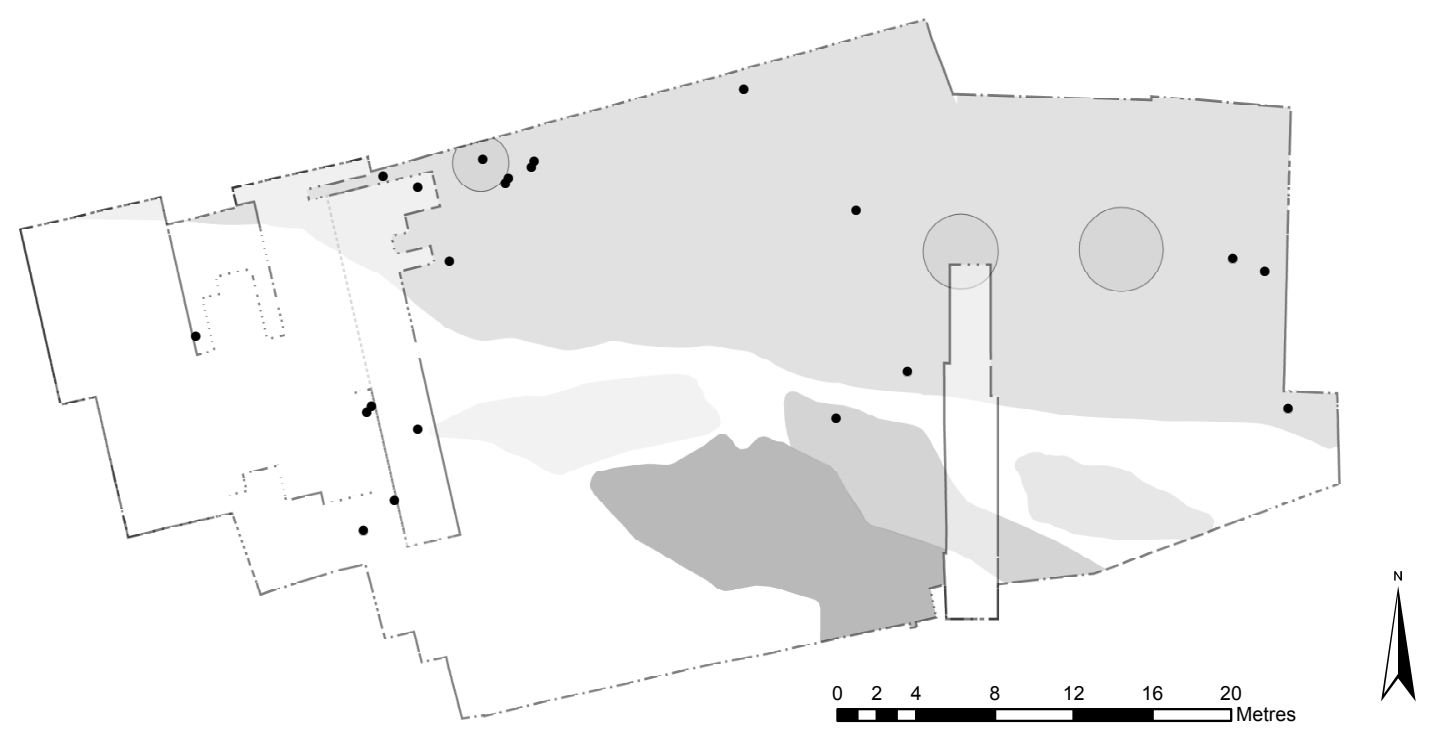

Figure 35.29: Distribution of microdenticulates (Copyright Star Carr Project, CC BY-NC 4.0). 


\section{$100 \mu \mathrm{m}$}

Figure 35.30: Transverse bone polish within notch of $<98438>(\times 20$ magnification) (Copyright Aimée Little, CC BY-NC 4.0).

\begin{tabular}{|l|l|l|r|}
\hline Primary contact material & Secondary contact material & Action & No. \\
\hline Wood & Plant (1), Bast (1) & Scrape (3), plane (1) & 4 \\
\hline Not used & & n/a & 3 \\
\hline Bone & & Scrape/shave & 2 \\
\hline Animal various & & Butchery & 1 \\
\hline Total & & & 10 \\
\hline
\end{tabular}

Table 35.18: Microwear analysis results for denticulates and notches.

artefacts associated with the central platform (see Chapter 8). A further two were recovered from Clark's area. More broadly notches and denticulates cluster in two main areas, in the axe workshop and in and around the western structure (Figure 35.31). All such tools analysed for microwear in these areas were used for woodworking, suggesting specialist activities, perhaps in the case of the axe workshop connected to haft preparation or the same woodworking tasks that involved use of the axes. 


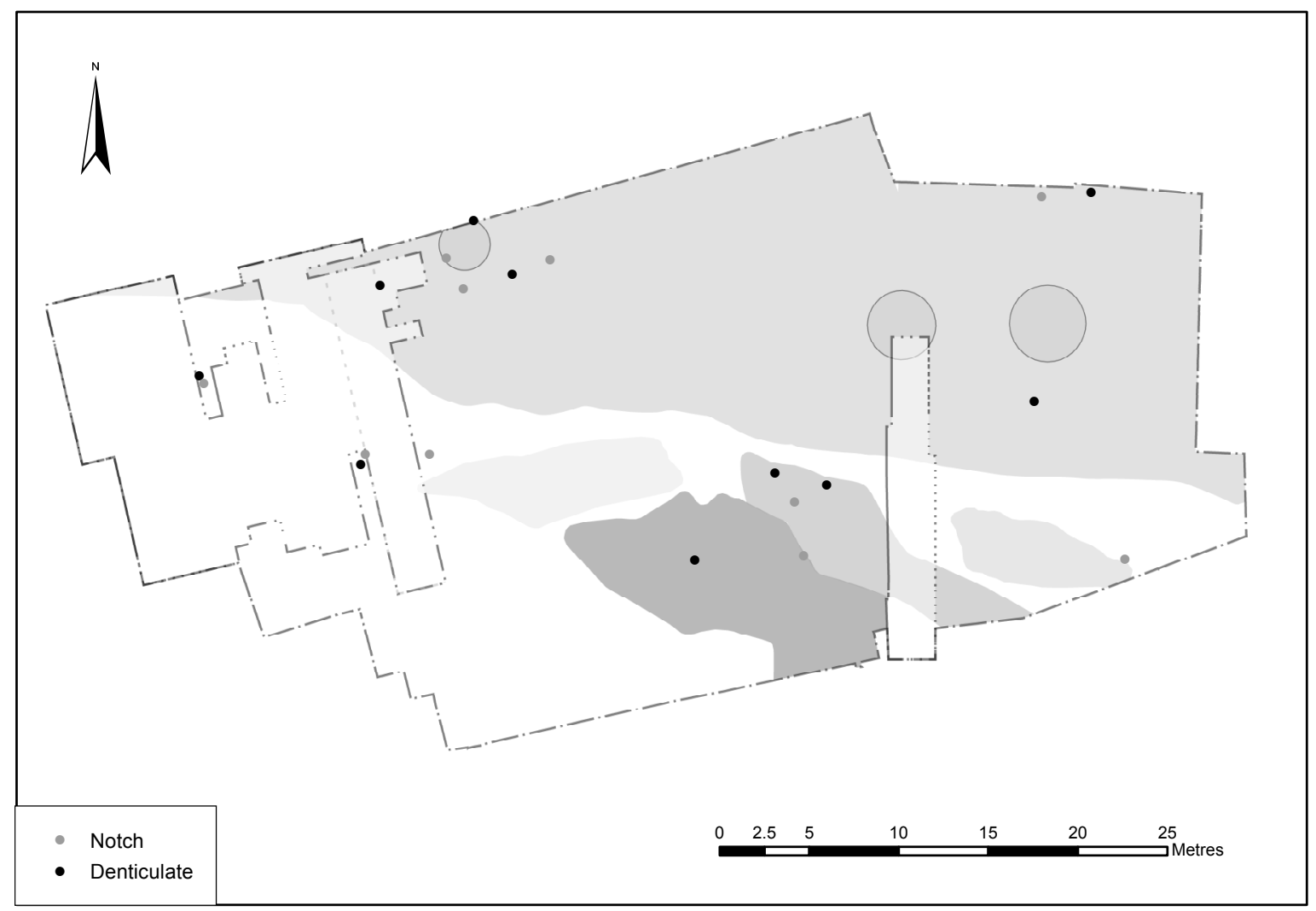

Figure 35.31: Distribution of notches and denticulates (Copyright Star Carr Project, CC BY-NC 4.0).

\section{Truncations}

Truncations are also relatively uncommon, with only 30 examples. With one exception, all are oblique truncations and on blades or bladelets. Most are distal truncations, though four are on the proximal and one is a double truncation. There is some overlap between the smaller examples and microliths. Lengths range from 13 to $62 \mathrm{~mm}$, widths from 10 to $29 \mathrm{~mm}$ and thickness from 2 to $8 \mathrm{~mm}$, with an average of $40 \times 17 \times 4.5$. The average of $40 \mathrm{~mm}$ compares with an average length of blades of $42 \mathrm{~mm}$. Given that some of the length would have been removed through the truncation process, it seems that larger than average supports have been selected. Truncations are found across the site, in dryland, wetland edge and wetland contexts. Three examples are associated with the western structure, and two with both the axe workshop and the fen carr scatter, and they are particularly common in the test pits of the eastern peninsula, to the east of SC23 (Figure 35.32).

Three truncations were analysed for microwear traces. Interestingly, all three displayed hafting traces in the form of edge damage, and all three had been used intensively, but on a variety of materials (bone and/or antler, siliceous plant, wood), and different actions (grooving, scraping/cutting, grooving/scraping). A good example is $<89878>$ (Figure 35.33), which appears to have been used in plant craftwork, involving intensive scraping of siliceous plants, probably reeds, with some cutting of soft wood. The multifunctionality of truncations as tools is perhaps not surprising given their morphology, with different working edges that can be used, amongst other things, to cut, scrape and groove. Such diversity and intensity of use is probably why they were hafted and why they were found in a variety of contexts across the site.

\section{Strike-a-lights}

Twenty strike-a-lights were recovered from site. These were all made on recycled cores, apart from one example made on an axe. Three were examined for microwear. All had mineral polish confirming their use as strike-a-lights 


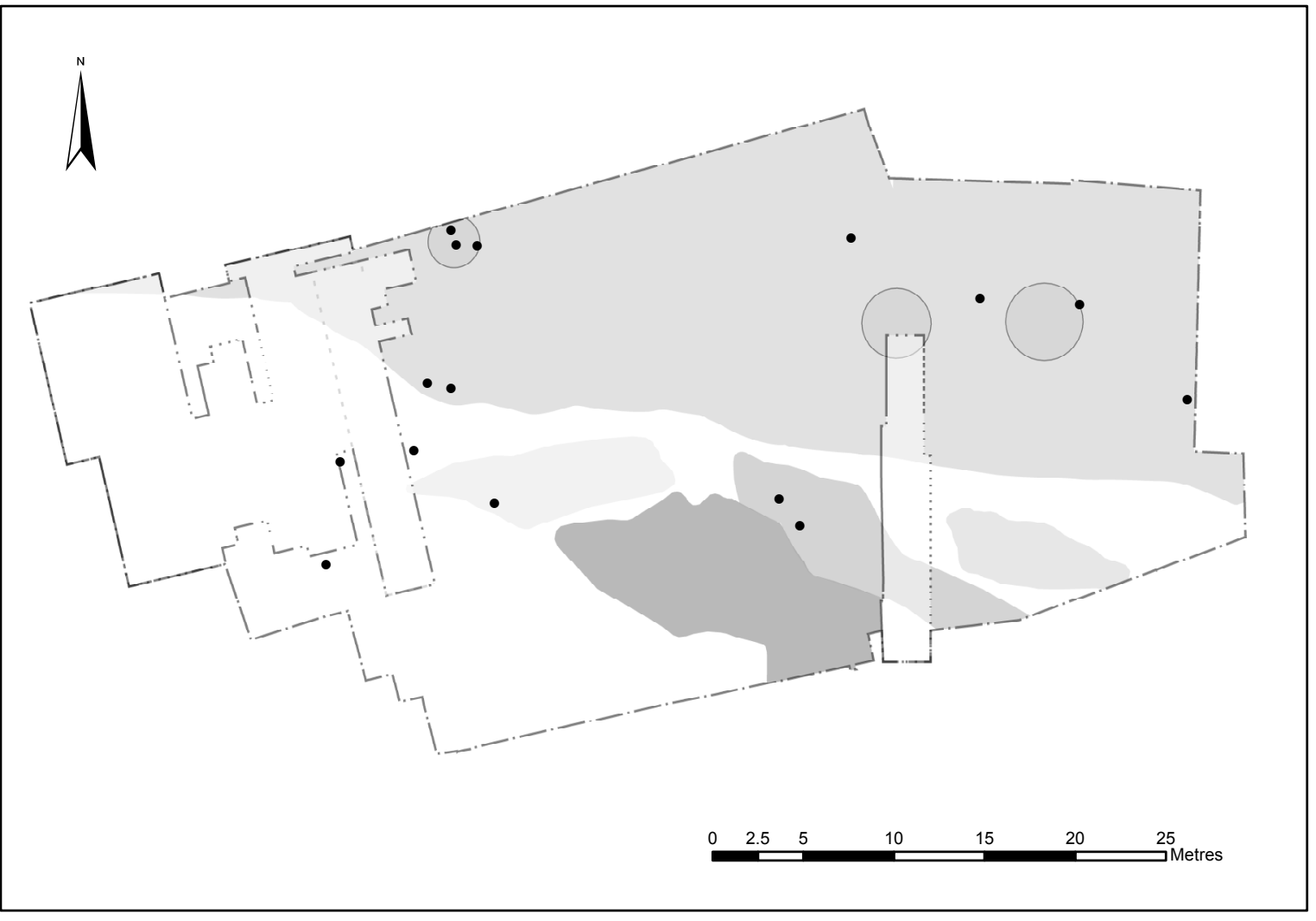

Figure 35.32: Distribution of truncations (Copyright Star Carr Project, CC BY-NC 4.0).

(Figure 35.33). The strike-a-lights are rarely found as isolated pieces (Figure 35.34). The largest cluster (of five) is found in a $6 \times 2 \mathrm{~m}$ area in the low-density area between the western and central structures. Three were recovered from scatter 7, a low-density discrete area of knapping, and a further three from the western structure.

\section{Blades and utilised blades}

Rather than functioning simply as blanks for future tool production, blades were frequently used as tools. As described above, many have macroscopic damage. This is particularly true of the larger examples with most blades above $65 \mathrm{~mm}$ showing evidence of macroscopic damage. Microwear indicates that blades were clearly multifunctional tools, used to scrape, cut, pierce, peel, bore and butcher a broad variety of contact materials. Of the 68 pieces analysed, just eight displayed no traces at all. Of the analysed blades, 33 had macroscopic damage identified by CC, of which only one had no evidence of use when examined for microwear. Of the 35 pieces with no obvious macroscopic damage, seven had no use traces. This indicates that macroscopic damage identified by the lithic specialist is a fairly good proxy for actual use, but that much used material leaves no visible traces. However, there was a very similar range of actual uses for those blades identified as 'utilised' to those where use was not macroscopically visible.

Thirteen blades were identified as displaying wear traces resulting from the working of various animal materials and have been classified as butchery tools (Table 35.19). These included blades, utilised blades, blade fragments and bladelets. Of the three bladelets with butchery traces, two belong to the X6 cache (see Chapter 8). The only butchery blade with hafting traces was a piece $<94931>$ that had been used intensively for this task, with very-well-developed traces. Seven blades had been used to work siliceous plants and seven had been used to work bone; some of these may also have been butchery tools, used in the later stages of carcass processing. 


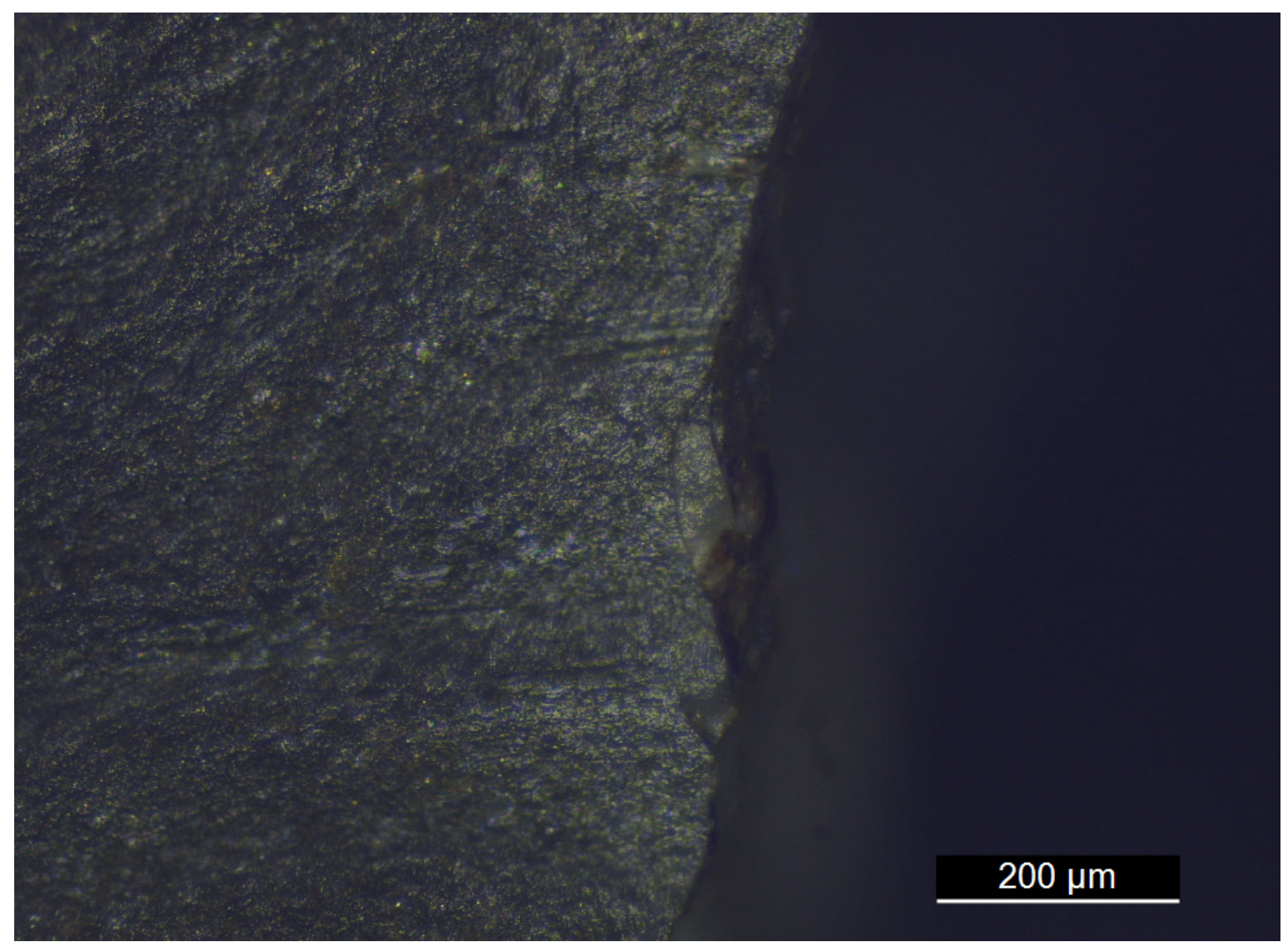

Figure 35.33: Transverse striations on strike-a-light <102669> (Copyright Aimée Little, CC BY-NC 4.0).

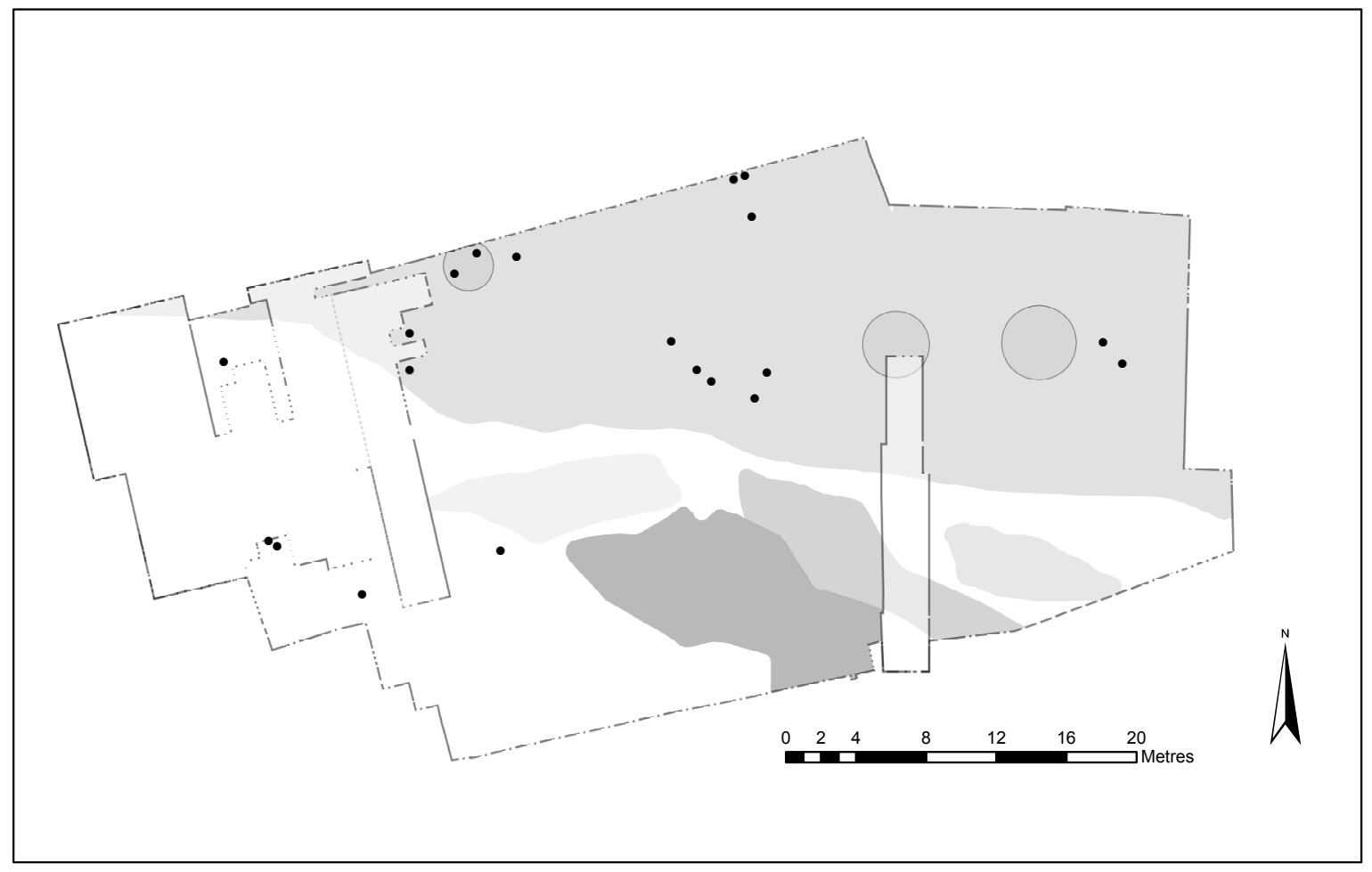

Figure 35.34: Distribution of strike-a-lights (Copyright Star Carr Project, CC BY-NC 4.0). 


\begin{tabular}{|l|l|l|l|r|}
\hline $\begin{array}{l}\text { Primary contact } \\
\text { material }\end{array}$ & $\begin{array}{l}\text { Secondary contact } \\
\text { material }\end{array}$ & $\begin{array}{l}\text { Tertiary } \\
\text { material }\end{array}$ & $\begin{array}{l}\text { Action } \\
\text { Various = more than 2 actions identified }\end{array}$ & No. \\
\hline Animal various & & & Butchery & 13 \\
\hline Not used & & & n/a & 8 \\
\hline Siliceous plant & Soft wood (2) & & $\begin{array}{l}\text { Scraping (3), Cutting (2), Cutting/scraping (1), } \\
\text { Various (1) }\end{array}$ & 8 \\
\hline Bone & & Boring (2), Scraping (2), Indet. (1) & 7 \\
\hline Wood & & Scraping (3), Various (1) & 5 \\
\hline Plant & & & Scraping (1), Scraping/piercing (1), Various (2) & 4 \\
\hline Hide & Mineral (3), Bone (1) & Bone (1) & 4 \\
\hline Antler? & Bone? & Scraping (1), Various (1) & 2 \\
\hline Impact & & Projectile & 2 \\
\hline Bast & Wood & Debarking & 1 \\
\hline Soft wood & Siliceous plant & & Cutting/scraping & 1 \\
\hline $\begin{array}{l}\text { Hard material } \\
\text { indet. }\end{array}$ & & & Cutting/scraping & 1 \\
\hline $\begin{array}{l}\text { Medium material } \\
\text { indet. }\end{array}$ & & & Piercing & 1 \\
\hline Un-analysable & & & n/a & 56 \\
\hline Indet. & & & Indet. & 4 \\
\hline Total & & & & \\
\hline
\end{tabular}

Table 35.19: Microwear analysis results for blades, utilised blades and bladelets.

At least one (bladelet $<107528>$ ) appears to have been a multifunctional craft tool, used to cut, scrape and groove dry bone. Just one bone-working blade <93629> displays clear signs of hafting; it was hafted directly into a hard material, probably bone or antler. Five blades had been used to work wood. On two of these, the distal tip had been used to bore wood, whilst two others had been used to scrape or whittle; both had hafting traces, the other displayed no clear directionality in traces. Four blades were used in hide-work; three of these also displayed mineral polish whilst one had also been used on bone. In all instances craftwork seems to have been the primary function of these tools, which were used to scrape, cut and pierce hide. Two blades had possibly been used on antler but neither had very well-developed traces. Because of the well-known difficulties in determining the difference between wood and antler polish, it is possible these tools were used on wood or even a combination of antler and wood. Two bladelets $(<116366>$ and $<102584>)$ displayed impact traces, indicating use as projectile points.

Eight flint blades displayed siliceous plant working traces (mostly scraping, but also some cutting), and a further four were identified as being used on a plant material (mostly scraping, but one was a multi-functional tool, probably used in craftwork). The siliceous plant polish on the Star Carr blades is typically transverse, sometimes oblique, indicating a scraping motion. This is commensurate with that produced during experimental work undertaken in order to replicate the numerous archaeological examples of unretouched flint blades and to a lesser extent, flakes, displaying these types of traces from Dutch Mesolithic and Early Neolithic wetland sites (van Gijn and Little 2016). Experiments demonstrated that unmodified replica blades used to scrape the stems of various siliceous plants (Typha, Juncus and Scirpus) produced the most comparable polish to that seen on the artefacts. It is probable that such tools were used to extract fibres and to make stems pliable for use in basketry, matting and so forth. At Star Carr, like at other North-West European sites, there appears to be a preference for blades with a slight curvature to one lateral margin for plant-working. Only one blade had possible hafting traces. In general, it appears that plant-working tools were handheld. 
Dumont analysed 18 edge-damaged and/or marginally retouched blades. Of these, 13 had wear traces, nine of which were wood. No siliceous plant-working traces were identified by Dumont at either Star Carr or Mount Sandel, which is curious given the prevalence of such evidence at other Mesolithic sites in North-West European (Little and van Gijn 2017; see also Perdaen et al. 2004). It is possible that Dumont was either not recognising these traces when in existence, or was subsuming them into the category of 'wood'. With respect to the latter, he states a reluctance to 'resolve the sub-types within each type of polish such as hard vs. soft wood' (Dumont 1983, 132). This potential oversight is important because, when compared with other sites of a broadly contemporary date, the function of tools and related/inferred activities at both Star Carr and Mount Sandel have assumed a much more animal-related focus, in keeping with broader economic trends popular at the time. Yet our analysis shows that different tools, but in particular, unmodified blades, were regularly used to work siliceous plants, probably reeds that would have grown along the lake edge (Chapter 19). In fact, two siliceous plant-working tools, when plotted (see Figure 8.5), are located adjacent to each other at the water's edge, providing an intimate insight of what was probably in situ plant-working activities in and amongst the reeds. A further striking spatial pattern is the high frequency of occurrence $(n=5)$ of blades with plant-working traces recovered from Clark's area, the meaning of which is unclear.

Utilised pieces are distributed across the site, in areas of knapping, tool use and deposition (Figure 35.35). Proportionally to other material, they have a very strong association with the wetlands. They have two areas of main concentration: in Clark's area and in the bead area. There is a strong association of utilised blades from the wetlands with plant working; possibly, on occasions at least, reflecting the harvesting of reeds along the lake edge, though for many of these tools, cutting as well as scraping was involved.

\section{Flakes and fragments}

Flakes, fragments and shatter fragments, generally seen as knapping waste, were also used as tools. Of the 34 pieces analysed, most had been used (Table 35.20).

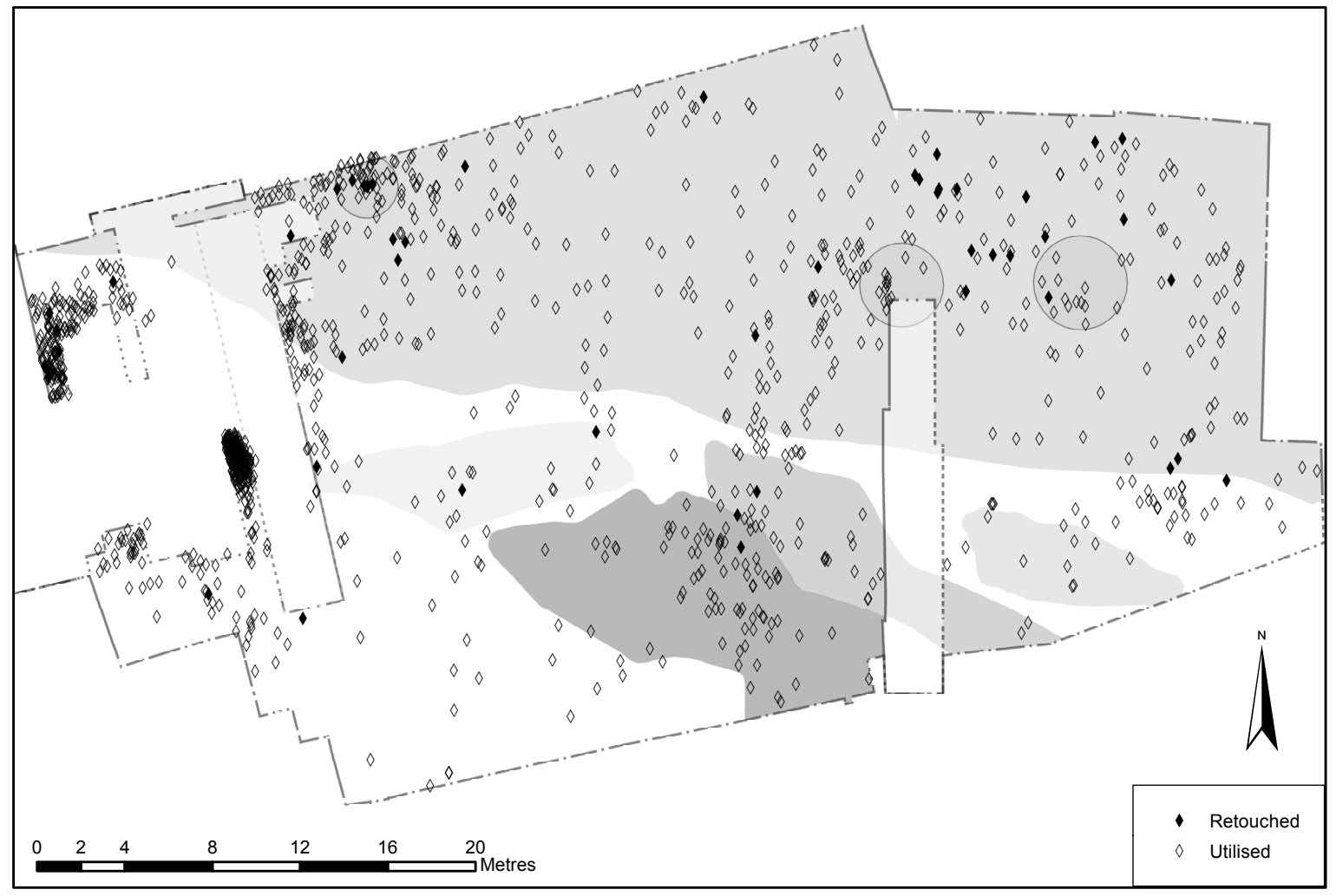

Figure 35.35: Miscellaneous retouched pieces, utilised blades, flakes and fragments (Copyright Star Carr Project, CC BY-NC 4.0). 


\begin{tabular}{|l|l|l|r|}
\hline Primary contact material & Secondary contact material & Action & No. \\
\hline Indet. use & & $\begin{array}{l}\text { Scraping (2; one of which was a hard material), } \\
\text { Indet. (6) }\end{array}$ & 8 \\
\hline Bone & Antler (1), Soft animal (1) & $\begin{array}{l}\text { Sawing/cutting (2), Scraping/cutting (1), Groove/ } \\
\text { Scrape/Cut (1), Grooving (1), Cutting (1) }\end{array}$ & 6 \\
\hline Wood & & Scraping & 4 \\
\hline Siliceous plant & Wood (1) & Planing/scraping/cutting (1), Cutting (1) & 2 \\
\hline Animal various & & Butchery & 2 \\
\hline Animal soft & & Butchery? & 1 \\
\hline Antler & & Cutting & 1 \\
\hline Plant & Indet. & 1 \\
\hline Meat & & Cutting & 1 \\
\hline Fish & & Cutting/scraping & 1 \\
\hline Mineral & & Scraping? & 1 \\
\hline Not used & n/a & 3 \\
\hline Total & & & 34 \\
\hline
\end{tabular}

Table 35.20: Microwear analysis results for flakes, fragments, chunks and nodules.

Microwear analysis of flakes, fragments and chunks showed a great variety of tool use functions. The largest quantity $(n=8)$ had indeterminate use traces. This was followed by bone $(n=6)$, animal various $(n=3)$, siliceous plant $(n=2)$ and plant $(n=1)$, with one each of the following: antler, meat, fish and mineral. All but one of the pieces with bone-working traces was identified on fragments, four of which belong to the X6 cache discussed in Chapter 8. The chunky nature of these forms was likely to have been a factor in their selection and use in the working of bone. All the pieces where wood is the primary contact material (worked in a scraping motion) came from the AC8 cache.

Three pieces displayed no use traces, which is surprisingly low considering the proportion of unused scrapers discussed above, and the likelihood of flakes, fragments and chunks representing manufacturing debris. The broad spectrum of contact materials and actions reflected in the microwear analysis results for this grouping of material reinforces the fact that 'debris' was very much utilised in everyday activities at Star Carr.

\section{Conclusions}

Rozoy and Rozoy (2004) have discussed the 'behaviour' of Mesolithic tools, and the current study has thrown new light on how tools were moved, curated and valued at this site. Some tools, such as axes were valued tools with extended life histories. They were not made at the site but were used extensively for chopping wood, most likely relating to the building of platforms and structures. Much effort was made to extend their lives through resharpening, often involving long sequences of reworking. Microwear suggests they were resharpened immediately or shortly after use, so that they would be ready for the next occasion, rather than being resharpened in response to an immediate need. They have a strong association with structures, where they were taken for resharpening and storage. Other tools, such as scrapers, seem more expedient, often abandoned in the same place as they were made. These too though were resharpened and on occasions were curated, being taken into the eastern structure for repair and storage. Awls may also have been relatively expedient tools; they certainly seem to have been abandoned in the same place that they were used. Burins have an intermediate position. They were, in general, curated sufficiently to be moved away from their place of manufacture, though occasionally they were used in the same place they were made. They are usually found abandoned with resharpening spalls, indicating discard in areas they were used. The aggregation of tools in the eastern structure suggests at least a household level of ownership of certain tools. 
Microwear, as expected, has problematised the equation of tools with their traditional uses, though perhaps not as much as expected. Axes are only associated with woodworking, and scrapers mainly with hide work. Burins have a much more varied set of uses, the most common of which is wood (though the difficulty of distinguishing wood and antler should be noted). Evidence for the use of burins as fish descalers should perhaps be considered more widely. Truncations, though few in number, seem to have been used in similar ways to burins (cf De Bie and Caspar 2000). Awls were used to pierce mineral, bone and hide, and thus seem to have been mainly focused on the production of clothing or other worn items. As seen on other North-West European wetland sites, unmodified blades were regularly utilised for plant-working, probably the scraping of locally growing reeds to extract and process fibres and/or preparing stems for use in basketry and/or matting (van Gijn and Little 2016). Microliths were not just projectiles, though that is their main use; they were used on different types of contact materials and had various functions, including craftwork. In addition, some started life as projectiles but were then re-used. Flakes, fragments, chunks, i.e. non formal tools, were regularly utilised: a useful reminder that an overemphasis on retouched tool types is useful for building typo-chronologies but does not necessarily reflect tool selection and subsequent utilisation. This, it appears, was guided by edge angle and flaked form, for example, the sharpness, robustness and/or angularity of a piece being considered in relation to the softness/hardness of the contact material, and the intended activity.

The combination of refitting and microwear has also permitted an understanding of the landscape "behaviour' of particular tools. While there was a wide variety of activities across the site, some tools and functions seem more associated with particular areas (see also Chapter 8). Some, such as burins and scrapers, were used across dryland and wetland contexts. Others have more restricted distributions. Axes tend to be found on dryland and wetland edge context, the latter at a stage when these areas were sufficiently dry to allow in situ flint knapping. Utilised blades are found across site, but are particularly common in wetland and wetland edge areas. These tools found in the wetlands also have a more restricted function, being used mainly for plant- and woodworking, but also for the killing and butchery of animals. Other activities took place off-site: the procurement of flint, the testing of nodules and the manufacturing of axes.

To this understanding of space we can also add a temporal dimension, as at least some of the lithic activities can be securely tied into the Bayesian model. There are suggestions of some changes in lithic materials over the temporal span the site was visited, with microlith forms possibly becoming more diverse, and then finally shifting towards forms more typical of Deepcar types. Procurement of till flint also possibly shows changes over time, most likely as a result of shifting morphology of proximate coastal areas. Activities on the dryland are varied and difficult to date; however, there are indications of change, with greater focus on bead production, and perhaps craft activities more broadly, in the middle and later phases of the site. Other activities stayed the same with strong similarities both in the sorts of lithic material found in the wetlands (mainly utilised blades) and the same restricted functions for this material persisting for several hundred years.

The lithic assemblage from Star Carr can be analysed with unusual precision, permitting a rare insight into the spatial and temporal dimensions of lithic-focused activities in the Early Mesolithic. In this we have been fortunate that we have had both the ability to excavate large areas and the presence of stratified wetland deposits permitting Bayesian modelling. However, patterns of lithic procurement, reduction, tool use and deposition are activities that take place across an entire landscape, not simply a single site, and to provide these landscape insights this chapter has drawn upon the decades of Mesolithic excavations undertaken around Lake Flixton as part of the Seamer project and later by the Vale of Pickering Research Trust. These endeavours have hugely enhanced this study of the lithic material, not least by being the stimulus for the current excavations. 